\title{
Monitoring soil moisture from middle to high elevation in Switzerland: set-up and first results from the SOMOMOUNT network
}

\author{
Cécile Pellet and Christian Hauck \\ Department of Geosciences, University of Fribourg, Fribourg, 1700, Switzerland \\ Correspondence to: Cécile Pellet (cecile.pellet@unifr.ch)
}

Received: 9 September 2016 - Discussion started: 14 September 2016

Revised: 5 May 2017 - Accepted: 23 May 2017 - Published: 29 June 2017

\begin{abstract}
Besides its important role in the energy and water balance at the soil-atmosphere interface, soil moisture can be a particular important factor in mountain environments since it influences the amount of freezing and thawing in the subsurface and can affect the stability of slopes.

In spite of its importance, the technical challenges and its strong spatial variability usually prevents soil moisture from being measured operationally at high and/or middle altitudes. This study describes the new Swiss soil moisture monitoring network SOMOMOUNT (soil moisture in mountainous terrain) launched in 2013. It consists of six entirely automated soil moisture stations distributed along an altitudinal gradient between the Jura Mountains and the Swiss Alps, ranging from 1205 to $3410 \mathrm{~m}$ a.s.l. in elevation. In addition to the standard instrumentation comprising frequency domain sensor and time domain reflectometry (TDR) sensors along vertical profiles, soil probes and meteorological data are available at each station.

In this contribution we present a detailed description of the SOMOMOUNT instrumentation and calibration procedures. Additionally, the liquid soil moisture (LSM) data collected during the first 3 years of the project are discussed with regard to their soil type and climate dependency as well as their altitudinal distribution. The observed elevation dependency of LSM is found to be non-linear, with an increase of the mean annual values up to $\sim 2000$ m a.s.l. followed by a decreasing trend towards higher elevations. This altitude threshold marks the change between precipitation/evaporation-controlled and frost-affected LSM regimes. The former is characterized by high LSM throughout the year and minimum values in summer, whereas the latter typically
\end{abstract}

exhibits long-lasting winter minimum LSM values and high variability during the summer.

\section{Introduction}

Soil moisture is a key factor controlling the energy and water exchange processes at the soil-atmosphere interface as well as the physical properties of the subsurface. The latter include also important properties for the thermal regime such as heat capacity and thermal conductivity (for a review see, e.g. Seneviratne et al., 2010). In 2010 soil moisture was classified as an essential climate variable by the Global Climate Observing System and has thus to be continuously and globally monitored. Even though the number of soil moisture networks is globally increasing, it is still far from being standardized, coordinated or spatially representative. Coordination efforts are however increasing with the International Soil Moisture Network being the largest soil moisture data source to date (Dorigo et al., 2011).

Existing soil moisture monitoring networks have many different foci, such as the validation of remote sensing products (e.g. Bircher et al., 2012; Rautiainen et al., 2012), the investigation of hydrological processes at hillslope scale (e.g. Brocca et al., 2007; Martini et al., 2015) or catchment scale (e.g. Bogena et al., 2010) as well as the study of landatmosphere interactions (e.g. Hauck et al., 2011; Krauss et al., 2010; Mittelbach et al., 2011). In the interest of representativeness for large-scale studies and due to easy implementation most of the current monitoring networks are located at middle to low elevation. In Switzerland, the long-term mon- 
itoring network SwissSMEX was initiated in 2008 and is composed of 16 stations distributed across the Swiss plateau and other low-elevation regions (Mittelbach and Seneviratne, 2012).

In mountain environments, soil moisture is particularly crucial since it can control the initiation of convective precipitation (e.g. Barthlott et al., 2011; Hauck et al., 2011), the generation of runoff (e.g. Morbidelli et al., 2016; Zehe et al., 2010) and thereby the mitigation or intensification of flash floods (e.g. Borga et al., 2007). Soil moisture also significantly affects the vegetation growth and distribution (e.g. Paschalis et al., 2015; Porporato et al., 2004). In terrains affected by seasonal and permanently frozen conditions, its effect on the stability of slopes and the thermal and kinematic characteristics of periglacial landforms was highlighted in several observation and modelling studies (e.g. Boike et al., 2008; Hasler et al., 2011; Hinkel et al., 2001; Krautblatter et al., 2012; Scherler et al., 2010; Streletskiy et al., 2014; Westermann et al., 2009; Zhou et al., 2015). A general overview of the interactions between hydrological, mechanical and ecological processes in frozen grounds is given by Hayashi (2013).

However, soil moisture measurements in mountainous areas are technically challenging because of the often coarse blocky substrate, the temperatures below the freezing point and the remoteness of the sites, which also adds difficulties regarding energy supply and data transfer. They are therefore also more costly to implement. Furthermore, among the numerous well established in situ soil moisture monitoring devices (e.g. Hillel, 2004; Robinson et al., 2008; Vereecken et al., 2014), only few have been tested in harsh and partly frozen conditions (e.g. Pellet et al., 2016; Rist and Phillips, 2005; Zhou et al., 2015). Thus, measurements in mountainous terrains are currently restricted to uncoordinated and project-based installations (e.g. Hilbich et al., 2011; Rist and Phillips, 2005; Zhou et al., 2015). Furthermore the systematic investigation of soil moisture along a large-elevation gradient reaching to Alpine permafrost conditions is nonexistent so far.

The project SOMOMOUNT (soil moisture in mountainous terrain; see also Pellet et al., 2016), which started in 2013 and is funded by the Swiss National Science Foundation, has the main objective of filling this data gap. In collaboration with the Swiss permafrost monitoring network (PERMOS) and the Swiss Federal Office for Meteorology and Climatology (MeteoSwiss), six automatic soil moisture monitoring stations have been established at different elevations.

In this contribution we will present a detailed description of the SOMOMOUNT monitoring network's instrumentation, monitoring strategy and calibration procedure, and discuss the accuracy of the measurements. Additionally, the data collected during the first 3 years of the SOMOMOUNT project will be discussed regarding the importance of the different water-related processes, which are dominant at the different elevation bands. Hereby the differential impact of a 3- week-lasting heat wave on the different sites during summer 2015 is highlighted.

\section{Soil moisture network}

The soil moisture network established within the framework of the SOMOMOUNT project is currently composed of six fully automatic soil moisture monitoring stations installed along an elevation gradient ranging from 1205 to $3410 \mathrm{~m}$ a.s.l., spanning from the Jura Mountains to the western Swiss Alps (Fig. 1). It is designed to be compatible with the existing low-elevation soil moisture monitoring network SwissSMEX (Mittelbach and Seneviratne, 2012) as well as the PERMOS stations. In addition, the high-elevation soil moisture and permafrost monitoring station of Cervinia, Italian Alps (Pellet et al., 2016; Pogliotti et al., 2015), is included in the comparative analyses.

\subsection{Instruments}

Three different types of sensors are used within the SOMOMOUNT network: the SMT100 (TRUEBNER GmbH, Germany), which is a frequency-based sensor, the TRIMEPICO64 (IMKO GmbH, Germany) based on time domain reflectometry (TDR) and the PR2/6 (Delta-T Devices Ltd, UK) based on the capacitance technique. Both the SMT100 and the PICO64 sensors are measuring simultaneously soil moisture and ground temperature. The sensor characteristics are listed in Table 1.

All methods are indirect measurement techniques that use electromagnetic waves to estimate the dielectric permittivity of the ground and relate it to liquid soil moisture (LSM). The SMT100 sensors are composed of a ring oscillator, which feeds a $10 \mathrm{~cm}$ long transmission line (Fig. 2). The sensors emit an electromagnetic pulse. Its resulting oscillation frequency is recorded and can then be related to the dielectric permittivity and thus to the LSM of the surrounding medium (see, e.g., Bogena et al., 2017; Qu et al., 2013). The SMT100 sensors are the newest generation of the SISOMOP sensors, which have been used to monitor LSM at Schilthorn (one of the high-elevation permafrost sites; see Sect. 2.3) since 2007 (Hilbich et al., 2011), demonstrating the sensors robustness and capability to measure in mountainous areas. Bogena et al. (2017) showed that the SMT100 sensors have an absolute accuracy of $\pm 1 \%$ vol in ideal conditions using the factory calibration.

The PICO64 sensors are based on the standard TDR technique, which relates the travel time of an electromagnetic wave to the dielectric permittivity of the medium surrounding the sensors, which can in turn be related to the LSM. The PICO64 sensors emit an electromagnetic impulse at a frequency of $1 \mathrm{GHz}$ along two $16 \mathrm{~cm}$ long parallel rods separated by $40 \mathrm{~mm}$, yielding a measurement volume of $\sim 1.25 \mathrm{~L}$ ( $\sim 10 \mathrm{~cm}$ diameter around the rods). The recorded travel 


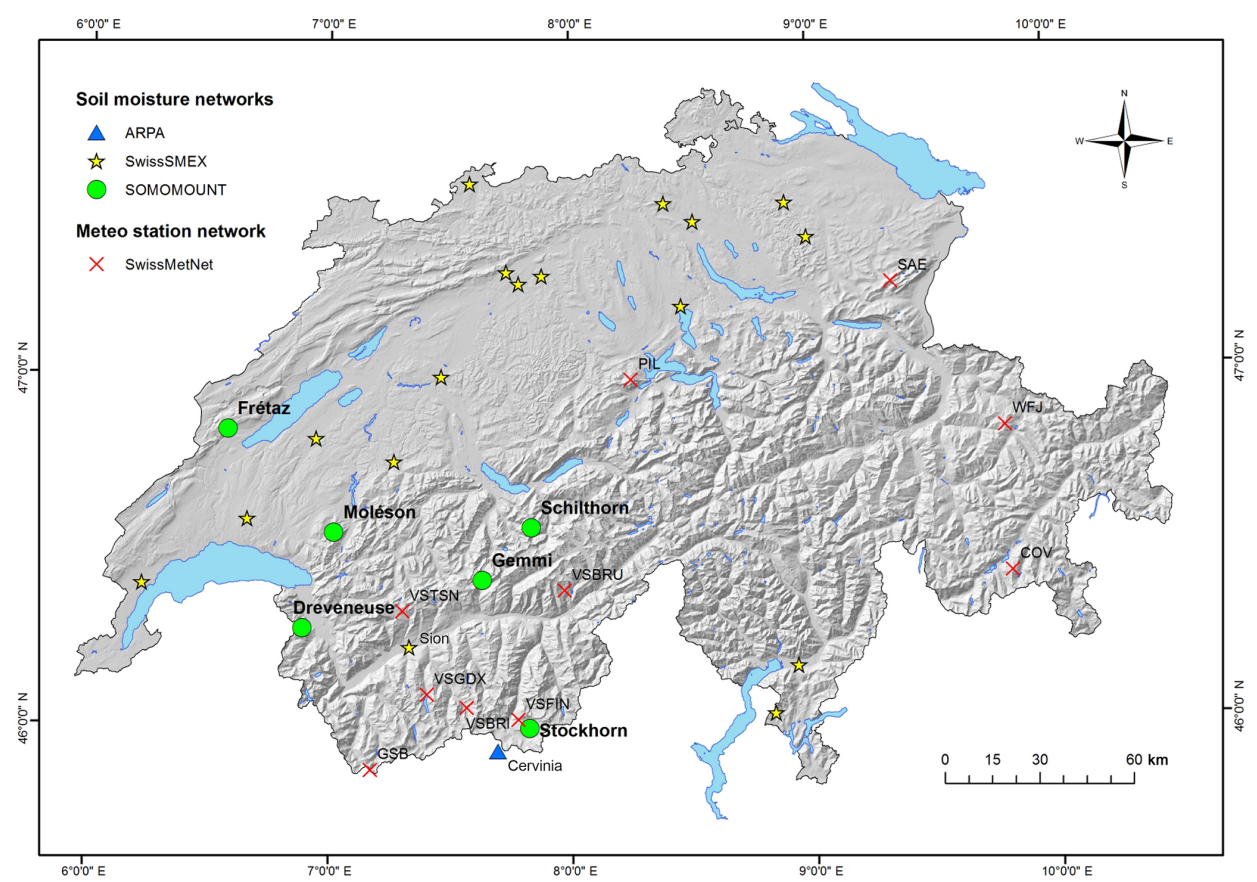

Figure 1. Map of Switzerland showing the location of the soil moisture monitoring stations from the SOMOMOUNT and SwissSMEX project (Mittelbach and Seneviratne, 2012) as well as the ARPA monitoring station Cervinia (Pogliotti et al., 2015). Selected mountain weather stations form the SwissMetNet network used in Sect. 5.2 are also displayed.

Table 1. Characteristics of the three types of soil moisture sensors used in the SOMOMOUNT network. All values in the table are provided by the manufacturers (Delta-T Devices, 2008; IMKO, 2015; Truebner, 2016).

\begin{tabular}{|c|c|c|c|c|}
\hline Sensors & Measurement technique & Range of LSM & Operating temperature & Accuracy \\
\hline SMT100 (Truebner GmbH, Germany) & Frequency domain & $\begin{array}{l}0 \text { to } 100 \% \text { vol } \\
\text { (60-100\% limited accuracy) }\end{array}$ & -40 to $60^{\circ} \mathrm{C}$ & $\begin{array}{l} \pm 3 \% \text { vol for } 0-50 \% \text { vol } \\
\pm 1 \% \text { vol using medium } \\
\text { specific calibration }\end{array}$ \\
\hline PICO64 (IMKO GmbH, Germany) & TDR & 0 to $100 \%$ vol & -15 to $50^{\circ} \mathrm{C}$ & $\begin{array}{l} \pm 1 \% \mathrm{vol} \text { for } 0-40 \% \mathrm{vol} \\
\pm 2 \% \mathrm{vol} \text { for } 40-70 \% \mathrm{vol}\end{array}$ \\
\hline PR2/6 (Delta-T Devices Ltd, UK) & Capacitance & 0 to $100 \% \mathrm{vol}$ & -20 to $60^{\circ} \mathrm{C}$ & $\begin{array}{l} \pm 6 \% \text { vol for } 0-40 \% \text { vol } \\
\pm 4 \% \text { vol using medium } \\
\text { specific calibration }\end{array}$ \\
\hline
\end{tabular}

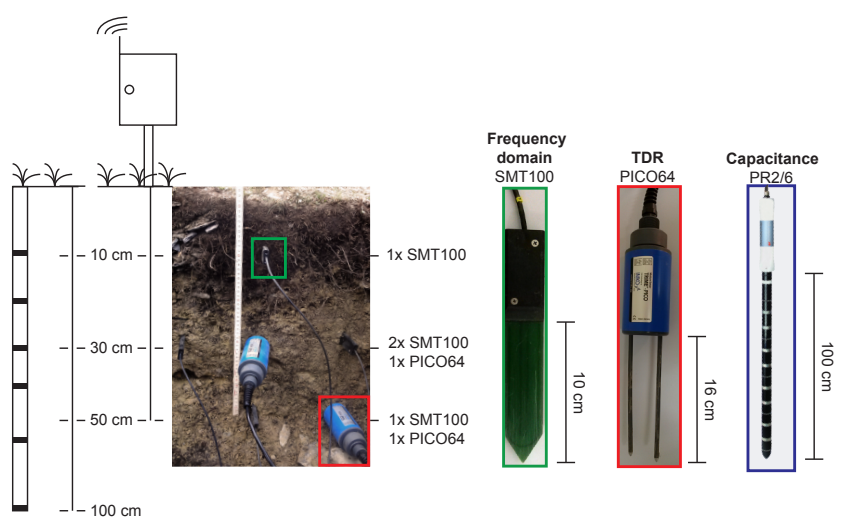

Figure 2. Instrumentation of the standard SOMOMOUNT station. times are related to the LSM using a general calibration based on Topp's equation (Topp et al., 1980). This sensor was selected for its high absolute accuracy ( $\pm 1 \%$ vol, IMKO, 2015) and because it corresponds to the new generation of TRIMEEZ sensors used by the SwissSMEX monitoring network (Mittelbach et al., 2011). Additionally, due to its large measurement volume, this sensor is particularly suitable for heterogeneous media (IMKO, 2015).

Finally, the PR2/6 sensor is a $100 \mathrm{~cm}$ long down-hole water content sensor measuring LSM at six different depths, using the capacitance technique (Fig. 2). Each measurement depth comprises a pair of stainless steel rings, which transmit the $100 \mathrm{MHz}$ electromagnetic signal into the ground, and one detector to record the returned signal. The sensor is lodged in an access polycarbonate tube of $25 \mathrm{~mm}$ diameter and its measurement volume is $\sim 10 \mathrm{~cm}$ diameter with an absolute 


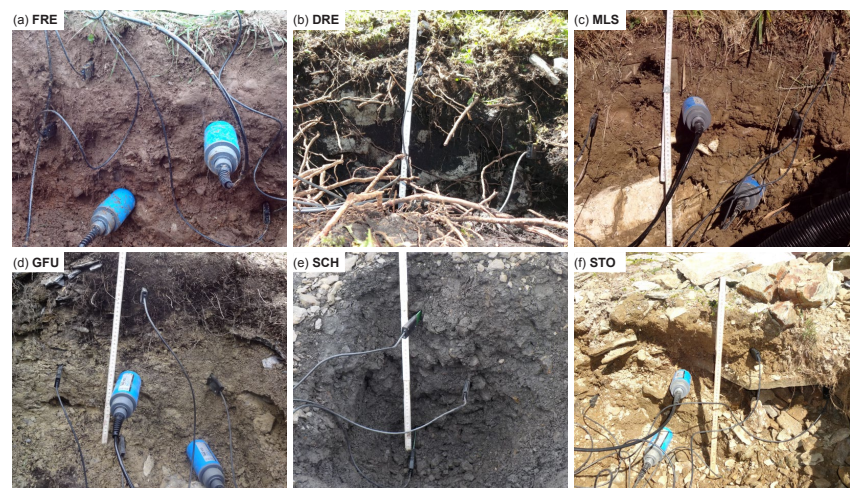

Figure 3. Illustration of the soil characteristics and sensor installation for all SOMOMOUNT stations.

accuracy of $\pm 6 \%$ vol (Delta-T Devices, 2008; Verhoef et al., 2006). This sensor was selected for its measurement depth and its easy installation. However, it is not suited for heterogeneous subsurface or coarse-grained material since a good contact between the access tube and the soil is necessary. Furthermore, at least $1 \mathrm{~m}$ soil is needed for its installation; thus, it was only used at Frétaz (Sect. 2.3).

\subsection{Network design}

Each soil moisture station is equipped with four to six sensors along a vertical profile. The standard instrumentation consists of one SMT100 at $10 \mathrm{~cm}$, two at $30 \mathrm{~cm}$ and one at $50 \mathrm{~cm}$ as well, as one PICO64 at $30 \mathrm{~cm}$ and one at $50 \mathrm{~cm}$ (Fig. 2). The doubled sensors at $30 \mathrm{~cm}$ were installed to check for long-term instrumental drift. Installation of the complete instrumentation at all depths was not possible at all sites due to soil characteristics. The site-specific set-ups are summarized in Table 2.

The same sensor installation procedure was followed at all sites and is based on the criteria described in Krauss et al. (2010) and Mittelbach et al. (2011). While digging the pit for the sensor installation, each soil horizon was stored separately in order to preserve and restore the initial soil profile. At the depth of each sensor, up to two soil samples were collected at the side for granulometric analysis and determination of water content. The sensors were then installed in the undisturbed soil with the blade in vertical position to avoid ponding (Figs. 2, 3). Finally, the soil was refilled according to the original order of horizons and compacted to restore its original density. Additionally, larger soil samples (about $8 \mathrm{~L}$ ) were collected in the vicinity for material-specific calibrations of the sensors (Sect. 3). Data are recorded using a CR1000 data logger (Campbell Scientific) and transmitted wirelessly to an ftp server. The measurement interval is depending on the electrical power capacity of each station (see Table 2).

\subsection{Field sites}

The site selection for the installation of the long-term soil moisture monitoring stations within the SOMOMOUNT project was constrained by the following criteria:

i. sufficiently high elevation, for the ground thermal regime to be affected by seasonally or permanently frozen conditions;

ii. equal distribution along an altitudinal gradient;

iii. availability of additional meteorological data and if possible ground temperature data;

iv. easy access on-site, and a minimum of $50 \mathrm{~cm}$ of finegrained material to guarantee the installation of the sensors.

The stations were installed in collaboration with MeteoSwiss (see SwissMetNet; http://www.meteoswiss.admin. ch) for stations at middle elevation and the Swiss Permafrost Monitoring Network PERMOS (http://www.permos.ch) for stations at higher elevation (see Table 2). Located in the western part of Switzerland, the SOMOMOUNT network covers an elevation range from 1205 to $3410 \mathrm{~m}$ a.s.l. with altitudinal differences between stations of 400-500 m (Fig. 1). Detailed information about the climatic conditions and subsurface properties at each field site are summarized in Table 3.

\subsubsection{Frétaz (FRE)}

Frétaz is located in the western part of Switzerland on the first crest of the Jura Mountains at an altitude of $1205 \mathrm{~m}$ a.s.l. The soil moisture monitoring station is installed within the perimeter of the weather station belonging to the MeteoSwiss automatic network SwissMetNet. In addition, ground temperatures down to $1 \mathrm{~m}$ depth were measured until 2005 .

The surface cover consists of managed grass following the general directives from MeteoSwiss (grass cover maintained at all times at a few $\mathrm{cm}$ ). The soil is composed of a unique layer of sandy loam down to $50 \mathrm{~cm}$ (Table 3). According to geophysical surveys (electrical resistivity tomography, ERT), the limestone bedrock is located at 5 to $10 \mathrm{~m}$ depth underneath the station (see Pellet et al., 2016).

\subsubsection{Dreveneuse (DRE)}

The Dreveneuse field site is located at an altitude of $1650 \mathrm{~m}$ a.s.l. in a small north-orientated valley within the Swiss pre-Alpine region, where the mean annual air temperature is around $5^{\circ} \mathrm{C}$ (Morard, 2011). The soil moisture station is installed on a vegetated talus slope near an automatic weather station, and ground temperatures are monitored in two boreholes down to 5 and $14 \mathrm{~m}$ depth, respectively.

This site is situated below the lower altitudinal limit of permafrost occurrence in the Alps but is still affected by permafrost conditions due to complex air circulation within the 
Table 2. Summary of the station instrumentation and characteristics at the field sites Frétaz (FRE), Dreveneuse (DRE), Moléson (MLS), Gemmi (GFU), Schilthorn (SCH) and Stockhorn (STO).

\begin{tabular}{lrrrrrrl}
\hline \multirow{2}{*}{ Site } & Elevation [m a.s.1.] & \multicolumn{3}{c}{ Sensor depth $[\mathrm{cm}]$} & \multirow{2}{*}{ Measurement interval } & Start date & Related networks \\
\cline { 3 - 5 } & & SMT100 & PICO64 & PR2/6 & \\
\hline FRE & 1205 & $10,30,30,50$ & 30,50 & $10,20,30,40,60,100$ & $10 \mathrm{~min}$ & 11.10 .2013 & SwissMetNet \\
DRE & 1650 & $10,30,30,50$ & - & - & $60 \mathrm{~min}$ & 26.09 .2014 & PERMOS \\
MLS & 1974 & $10,30,30,50$ & 30,50 & - & $10 \mathrm{~min}$ & 17.10 .2013 & SwissMetNet \\
GFU & 2450 & $10,30,30,50$ & 30,50 & - & $30 \mathrm{~min}$ & 17.07 .2013 & PERMOS \\
SCH & 2900 & $10,30,50$ & 10 & - & $30 \mathrm{~min}$ & 31.07 .2014 & PERMOS \\
STO & 3410 & $10,30,30,50$ & 30,50 & - & $30 \mathrm{~min}$ & 27.08 .2014 & PERMOS \\
\hline
\end{tabular}

Table 3. Summary of the climatic conditions and soil properties at each SOMOMOUNT station.

\begin{tabular}{|c|c|c|c|c|c|c|c|c|c|c|c|}
\hline \multirow[t]{2}{*}{ Site } & \multirow{2}{*}{$\begin{array}{l}\text { Elevation } \\
\text { [ma.s.l.] }\end{array}$} & \multirow{2}{*}{$\begin{array}{c}T_{\text {air }}^{\mathrm{a}} \\
{\left[{ }^{\circ} \mathrm{C}\right]}\end{array}$} & \multirow{2}{*}{$\begin{array}{r}P^{\mathrm{a}} \\
{[\mathrm{mm}]}\end{array}$} & \multirow{2}{*}{$\begin{array}{l}\text { Depth } \\
{[\mathrm{cm}]}\end{array}$} & \multicolumn{3}{|c|}{ Particle size distribution [\%] } & \multirow[t]{2}{*}{ Texture $^{b}$} & \multirow{2}{*}{$\begin{array}{l}\text { Bulk density } \\
\qquad\left[\mathrm{g} \mathrm{cm}^{-3}\right]\end{array}$} & \multirow{2}{*}{$\begin{array}{r}\text { Organic fraction } \\
\qquad \%]\end{array}$} & \multirow[t]{2}{*}{ Thermal regime } \\
\hline & & & & & Clay & Silt & Sand & & & & \\
\hline \multirow[t]{3}{*}{ FRE } & 1205 & 6 & 1333 & $0-10$ & 2.2 & 33.3 & 52.4 & Sandy Loam & 0.95 & 0.1 & No frost \\
\hline & & & & $10-30$ & 2.5 & 36.1 & 39.3 & Sandy loam & 1.06 & - & \\
\hline & & & & $30-50$ & 3.0 & 30.8 & 53.7 & Sandy loam & 1.01 & - & \\
\hline DRE & 1650 & 5 & 936 & $0-50$ & 0.6 & 24.4 & 71.3 & Sandy loam & 0.12 & 7.7 & Permafrost \\
\hline \multirow[t]{2}{*}{ MLS } & 1974 & 3 & 929 & $0-10$ & 11.8 & 72.5 & 15.6 & Silty loam & 0.58 & 0.15 & Seasonal frost \\
\hline & & & & $10-30$ & 15.1 & 77.6 & 7.1 & Silty loam & 0.71 & - & \\
\hline \multirow[t]{3}{*}{ GFU } & 2450 & 0 & $1800-2500$ & $0-10$ & 2.0 & 63.3 & 34.2 & Silty loam & 0.58 & 4.80 & Seasonal frost \\
\hline & & & & $10-30$ & 2.1 & 39.7 & 27.8 & Loam & 1.52 & - & \\
\hline & & & & $30-50$ & 2.6 & 46.5 & 39.8 & Sandy loam & 1.39 & - & \\
\hline \multirow[t]{2}{*}{$\mathrm{SCH}$} & 2900 & -3 & 2700 & $0-10$ & 1.0 & 14.5 & 60.0 & Loamy Sand & 1.53 & - & Permafrost \\
\hline & & & & $10-30$ & 0.6 & 8.7 & 40.6 & Sand & 1.35 & - & \\
\hline \multirow[t]{3}{*}{ STO } & 3400 & -5 & 1500 & $0-10$ & 0.3 & 6.4 & 48.7 & Sand & 1.42 & - & Permafrost \\
\hline & & & & $10-30$ & 0.6 & 20.4 & 56.5 & Loamy sand & 1.67 & - & \\
\hline & & & & $30-50$ & 0.7 & 21.6 & 58.9 & Loamy sand & 1.54 & - & \\
\hline
\end{tabular}

a Data source: MeteoSwiss at FRE and MLS; Morard (2011) at DRE; Krummenacher et al. (2008) at GFU; Imhof et al. (2000) and PERMOS at SCH; King (1990) and PERMOS at STO;

$\mathrm{b}$ According to the USDA classification

talus slope (Delaloye, 2004). The coarse limestone blocks composing the talus slope are covered by a single layer of organic-rich sandy loam (Table 3, Fig. 3b). The surface is covered by moss and spruces and according to repeated ERT soundings as well as drilling logs, the talus slope is approximatively $11 \mathrm{~m}$ thick (Morard, 2011).

\subsubsection{Moléson (MLS)}

The Moléson soil moisture station is situated at $1974 \mathrm{~m}$ a.s.l. on top of the eponym mountain in the Swiss pre-Alpine region. For the reference period 1981 to 2010 the mean annual air temperature was $3{ }^{\circ} \mathrm{C}$ and the annual sum of precipitation is $929 \mathrm{~mm} \mathrm{yr}^{-1}$ (MeteoSwiss). As for FRE, the soil moisture station is integrated within the perimeter of a SwissMetNet station, where the surface cover consists of managed grass.

No apparent layering was found in the soil profile (homogeneous layer of silty loam down to $50 \mathrm{~cm}$; see Fig. 3 and Table 3). According to ERT measurements and the construction journal of the weather station, the bedrock, which consists of limestone, is located at around $75 \mathrm{~cm}$ depth underneath the station.

\subsubsection{Gemmi (GFU)}

The Gemmi soil moisture monitoring station is located at $2450 \mathrm{~m}$ a.s.l. in a west-orientated valley within the main Alpine ridge of Switzerland (Fig. 1). The monitoring station is installed on a solifluction lobe in the direct vicinity of a $1 \mathrm{~m}$ deep temperature profile and a weather station (Krummenacher and Budminger, 1992).

This site is situated just below the lower limit of permafrost occurrence in the Alps and therefore undergoes marked seasonal freezing processes down to at least $1 \mathrm{~m}$ depth. The surface is covered by grass during the summer and the uppermost $10 \mathrm{~cm}$ of the ground is composed of an organic-rich silty loam layer (Table 3, Fig. 3). According to ERT measurements performed in 2014, the bedrock is located at around $5 \mathrm{~m}$ depth underneath the station (Pellet et al., 2016). 


\subsubsection{Schilthorn $(\mathrm{SCH})$}

The Schilthorn field site is situated at an elevation of $2900 \mathrm{~m}$ a.s.l. on a small plateau in the north-facing slope of the Schilthorn summit in the northern Swiss Alps (Fig. 1). The soil moisture station is installed next to an automatic weather station and three boreholes, where ground temperatures have been monitored since 1998 (Harris et al., 2001).

Permafrost is present at $\mathrm{SCH}$ and the depth of the seasonally unfrozen soil layer (the active layer) can reach up to $10 \mathrm{~m}$ (PERMOS, 2016). The surface cover is vegetation free and consists of a layer of fine-grained debris with material ranging from loamy sand to sand (Table 3) reaching several metres thickness according to ERT measurements (Hilbich et al., 2008). SCH is the only station of the SOMOMOUNT network where soil moisture has already been monitored since end of August 2007 (Hilbich et al., 2011).

\subsubsection{Stockhorn (STO)}

The highest soil moisture monitoring station of the SOMOMOUNT network is located at an elevation of $3410 \mathrm{~m}$ a.s.l. on the Stockhorn plateau in the western Swiss Alps. The soil moisture station is installed in the vicinity of an automatic weather station as well as two boreholes measuring ground temperatures since summer 2000 (Harris et al., 2001).

The Stockhorn plateau is underlain by at least $100 \mathrm{~m}$ deep permafrost (Gruber et al., 2004), where the active layer thickness can reach up to $5 \mathrm{~m}$ (PERMOS, 2016). The surface is free of vegetation and consists of a $1 \mathrm{~m}$ deep layer of finegrained debris ranging from sand to loamy sand (Table 3) underlain by Albit-Muskovit schist bedrock (Gruber et al., 2004).

\subsubsection{Additional stations}

In addition to the SOMOMOUNT network, we used the stations of Sion (SIO; Mittelbach and Seneviratne, 2012) and Cervinia (CER; Pellet et al., 2016; Pogliotti et al., 2015) for comparative analysis. The first one is part of the SwissSMEX network and is located in the Rhone valley at an elevation of $490 \mathrm{~m}$ a.s.1. Since 2009, LSM is measured down to $80 \mathrm{~cm}$ depth within the perimeter of the SwissMetNet station. Conversely, Cervinia is a high-elevation (3100 m a.s.1.) permafrost monitoring site managed by the regional environmental protection agency of Val d'Aosta (ARPA). Since 2006, the site is equipped with two boreholes ( 7 and $14 \mathrm{~m}$ deep) as well as an automatic weather station and one soil moisture sensor at $20 \mathrm{~cm}$ depth.

\subsection{Data processing}

To ensure the quality of the LSM and ground temperature data, two different automatic filters are applied: a technical filter and a temporal filter. The filters are based on guidelines from Dorigo et al. (2013).
The technical filter is designed to eliminate all unrealistic values due to technical issues. First, a threshold method is applied to detect and remove measurements outside of the plausible ranges $(<0$ and $>80 \%$ vol for LSM and $<-20$ and $>30^{\circ} \mathrm{C}$ for ground temperature). The threshold for LSM used here was empirically determined based on the data from all SOMOMOUNT stations. It is slightly higher than the $60 \%$ vol proposed by Dorigo et al. (2013) for the International Soil Moisture Network. Second, the values collected with insufficient battery voltage $(<10 \mathrm{~V})$ are removed, since too low power supply can disturb the measurements. For the SMT100 sensors, readings with a raw sensor output (given in moisture counts, MC; see Truebner, 2016) outside of the laboratory-defined range $\left(\mathrm{MC}_{\mathrm{water}} \approx 9000\right.$ and $\mathrm{MC}_{\mathrm{air}} \approx 20000$ ) are also excluded. At all sites the technical filter eliminated less than $0.1 \%$ of the measured values except at GFU, where the PICO64 sensors had a default in wiring and thus $8.3 \%$ of the measured data had to be excluded.

The temporal filter is designed to eliminate any value exhibiting unrealistically large temporal variability (random spikes); 3-day-running means $\left(r_{\text {mean }}\right)$ and standard deviations $\left(r_{\mathrm{SD}}\right)$ are calculated for all sensors. Measurement values lying outside of the range defined by $r_{\text {mean }} \pm x \cdot r_{\mathrm{SD}}$ are subsequently removed, where $x$ is an empirically determined site-specific tolerance factor ( 3 at FRE and GFU, 4 at DRE, SCH and STO and 5 at MLS). This filter was applied to LSM and ground temperature measurements with an elimination rate varying between $0 \%$ (DRE) and $0.3 \%$ (FRE and $\mathrm{SCH}$ ) of the measured data.

Numerous data gaps occurred at the different SOMOMOUNT stations during the monitoring period 2013-2016 (see Fig. 6). They were mainly caused by problems related to power supply (large data gap for all the sensors at a station, e.g. autumn 2013 at FRE and MLS), data logging (short gaps for all sensors of a station, e.g., winter 2014 at GFU) or sensor malfunction (single sensors for variable time, e.g., PICO64 at $50 \mathrm{~cm}$ at the end of summer 2016 at STO). Given the highly variable nature of LSM, no gap filling technique was applied.

\subsection{Complementary analysis}

All LSM datasets used in the following analysis were homogenized to hourly arithmetic mean values. For the elevation dependency investigation (Sect. 5.2), annual and seasonal means were calculated for the year 2015, since all stations except GFU have complete data series during that period. The data gaps at GFU (24 February-1 March 2015 and 24 April25 May 2015) were filled for this specific analysis only by linear interpolation between the nearest available data points. Finally, for the analysis of the moisture transport through the ground we used the moisture orbits (see Sect. 5.1).

To analyse and understand the temporal evolution of LSM in detail, additional datasets, such as weather and ground 
Table 4. Parameters and statistics of the linear and exponential calibration curve for each station.

\begin{tabular}{|c|c|c|c|c|c|c|c|c|c|}
\hline \multirow[t]{2}{*}{ Site } & \multicolumn{4}{|c|}{ Linear fit } & \multicolumn{4}{|c|}{ Exponential fit } & \multirow[t]{2}{*}{$n$} \\
\hline & $a$ & $b$ & $r^{2}$ & RMSE [vol.\%] & $c$ & $d$ & $r^{2}$ & RMSE [vol.\%] & \\
\hline FRE & -0.005630 & 98.15 & 0.96 & 2.76 & 707.1 & -0.0002680 & 0.93 & 3.66 & 16 \\
\hline DRE & -0.006361 & 114.7 & 0.89 & 5.71 & 1219 & -0.0002889 & 0.96 & 3.51 & 12 \\
\hline MLS & -0.008108 & 139.2 & 0.97 & 3.59 & 741.7 & -0.0002507 & 0.95 & 5.03 & 16 \\
\hline $\mathrm{GFU}_{\min }$ & -0.005327 & 93.7 & 0.80 & 5.57 & 465.8 & -0.0002336 & 0.75 & 6.18 & 13 \\
\hline $\mathrm{GFU}_{\text {org }}$ & -0.007819 & 140.2 & 0.95 & 3.93 & 534.2 & -0.000209 & 0.93 & 4.83 & 14 \\
\hline $\mathrm{SCH}$ & -0.004301 & 77.55 & 0.81 & 4.47 & 899.2 & -0.0002925 & 0.88 & 3.57 & 12 \\
\hline STO & -0.004851 & 85.71 & 0.84 & 4.02 & 457.9 & -0.0002378 & 0.79 & 4.58 & 18 \\
\hline
\end{tabular}

temperature data, are needed. The stations of SIO, FRE and MLS are located next to SwissMetNet stations and thus datasets with good quality are available. This is not always the case at the high-altitude/permafrost stations DRE, GFU, SCH and STO, where high-altitude-related logistical problems in maintenance lead to data gaps and precipitation is often not measured at all.

For the stations without explicit precipitation measurements, precipitation data were extracted from the $2 \mathrm{~km}$ gridded dataset generated by MeteoSwiss (MeteoSwiss, 2014), which is available at daily resolution and is based on $430 \mathrm{ob}-$ servation stations across Switzerland. Data gaps in the in situ measured air temperature series were completed using the two step quantile mapping approach described in Rajczak et al. (2016). Finally, snow cover duration was extracted from the ground-surface temperature variability using the snow index method described in Staub and Delaloye (2017).

\section{Calibration}

In order to increase the accuracy of the absolute LSM measurements, the SMT100 sensors require a material-specific calibration (Table 4). Using the large soil samples collected at each site, a material-specific calibration was performed in the laboratory following the general procedure outlined by Starr and Paltineanu (2002).

In a first step, the entire soil sample was oven dried and packed into a plastic container at approximatively the field bulk density (see Table 3). A SMT100 sensor was then inserted in the sample and its raw outputs were continuously recorded. Finally, a soil sample was collected using a standard $100 \mathrm{~cm}^{3}$ measurement cylinder. In a second step, $200 \mathrm{~mL}$ of water was added (LSM increase by about 3$5 \% \mathrm{vol}$ ) with subsequent mixing to get a homogenous repartition of the water in the calibration sample. The SMT100 was then reinserted, its raw outputs recorded and a soil sample collected. This procedure was repeated until saturation of the soil material was reached, yielding 9 to 12 calibration data points depending on the soil type.

The LSM $\left(\theta_{\mathrm{v}}\right)$ of the collected samples was determined following the standard gravimetric method. For this, the sam- ples were weighted and oven dried at $105^{\circ} \mathrm{C}$ during $24 \mathrm{~h}$ for the mineral soils and $60^{\circ} \mathrm{C}$ during $48 \mathrm{~h}$ for organic soils. The dry samples were then weighted to determine the gravimetric water content (mass of water which evaporated $\theta_{\mathrm{g}}$ ) and to calculate the dry bulk density $\left(\rho_{\mathrm{b}}\right)$. Finally, $\theta_{\mathrm{v}}$ was obtained using Eq. (1):

$\theta_{\mathrm{v}}=\rho_{\mathrm{b}} \cdot \theta_{\mathrm{g}}$

The gravimetric method was also applied to the in situ soil samples collected during the sensor installation. The calculated LSM $\left(\theta_{\mathrm{v}}\right)$ values obtained from both the laboratory and the in situ samples were then fitted to the SMT100 raw data (MC) using a linear (Eq. 2) and an exponential relation (Eq. 3).

$\theta_{\mathrm{v}}=a \cdot \mathrm{MC}+b$

$\theta_{\mathrm{v}}=c \cdot e^{(\mathrm{MC} \cdot d)}$

Table 4 lists the value of the parameters $a, b, c$ and $d$ for each station, the number of samples considered and the goodness of the fit for both methods. At GFU, two different materialspecific calibrations for mineral and organic soil were realized due to the clear layering of the soil profile (Fig. 3). At all locations except DRE the linear relation yields higher $r^{2}$ and lower root mean square error (RMSE) than the exponential relation. Thus, the linear calibration is used for all sites except DRE, where the exponential calibration is used.

For the PICO64, the built-in calibration based on Topp's equation (Topp et al., 1980) was used and no additional material-specific calibration was performed. In this study the PICO64 sensors are only used for inter-network comparison with the SwissSMEX network but not for further analysis. Thus, for consistency we adopted the same calibration approach as Mittelbach et al. (2011) (i.e. the built-in calibration for generic soils).

Similarly, the manufacturer's calibration was used for the PR2/6 sensor (Delta-T Devices, 2008), which is mainly used for test purposes within the SOMOMOUNT network. Depending on the middle-term results further PR2/6 sensors might later be added to the network.

Given the application of the various soil moisture sensors at field sites undergoing freezing and thawing processes, 

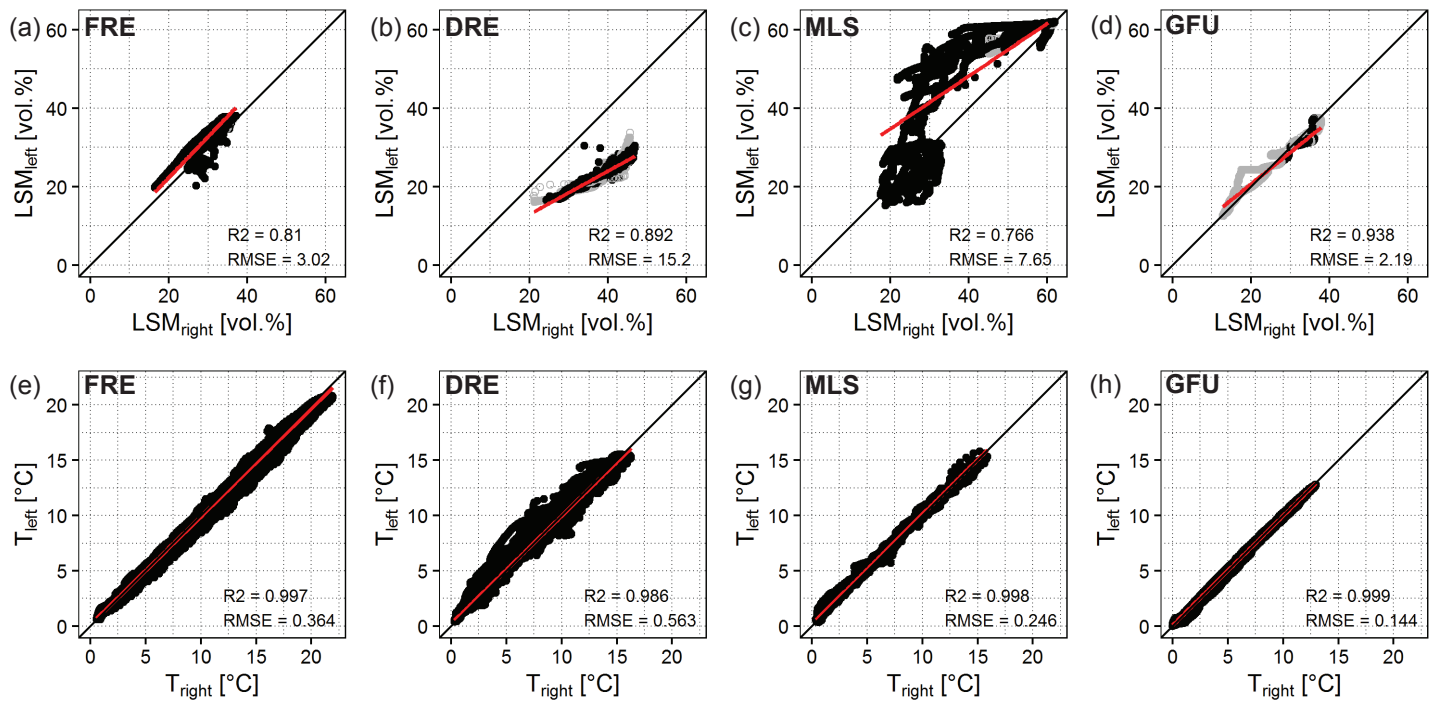

Figure 4. Comparison of measured LSM (upper row) and ground temperature (lower row) from both SMT100 sensors at $30 \mathrm{~cm}$ depth using the linear calibration at FRE (a, e), DRE (b, f), MLS (c, g) and GFU $(\mathbf{d}, \mathbf{h})$. The hollow grey points represent LSM measurements taken when the ground temperature was below $1^{\circ} \mathrm{C}$.

some considerations are important to make. As mentioned above the frequency based, capacitance and TDR techniques make use of the high permittivity of liquid water $(\sim 80)$ compared to the surrounding soil and air ( $2-9$ and 1 , respectively) to relate the recorded electromagnetic signal to LSM. However, the permittivity of liquid water is sensitive to temperature variations and can increase from $\sim 80$ at $20^{\circ} \mathrm{C}$ up to $\sim 88$ at $0^{\circ} \mathrm{C}$ (e.g. Wraith and Or, 1999), thus introducing an additional uncertainty in the calibration for unfrozen conditions. Furthermore, under frozen conditions a part of this total water turns into ice, having again a much lower permittivity ( $\sim 2-3$; e.g. Aragones et al., 2011). Thus, upon freezing, the recorded signal and measured LSM strongly decreases although the total soil moisture stays constant.

Characteristically, at temperatures below $0{ }^{\circ} \mathrm{C}$ water and ice can coexist in the soil (e.g. Spaans and Baker, 1995). However, the presented calibration procedure was conducted at room temperature and thus does not account for the presence of ice in the soil mixture. The resulting sensor accuracy is therefore only valid for above $0{ }^{\circ} \mathrm{C}$ ground temperatures (unfrozen conditions). The use of standard empirical calibration in frozen conditions often yields overestimations of the LSM (e.g. Spaans and Baker, 1995; Yoshikawa and Overduin, 2005). For frozen sand, however, Watanabe and Wake (2009) showed that TDR devices calibrated using Topp's equation exhibit only small deviations from the measured LSM using nuclear magnetic resonance (NMR) except at temperatures between 0 and $-1{ }^{\circ} \mathrm{C}$.

Although the absolute accuracy of measured LSM under frozen conditions is difficult to assess, its relative changes are well captured. At SCH, Hilbich et al. (2011) showed that the soil apparent resistivity (using data from continuous ERT monitoring) and LSM (measured with the precursor model of the SMT100) exhibit consistent variations under frozen and unfrozen conditions. Given the sandy composition of the ground at SCH and STO, as well as the evidence from the coinciding resistivity measurements (see also Hauck, 2002), we find the LSM data with standard calibration to be consistent enough for further analysis. Given the generally lower accuracy of the soil moisture sensors under partially frozen and frozen conditions, the LSM measurements carried out at temperatures below $1^{\circ} \mathrm{C}$ are clearly identified in all figures hereafter. The $1^{\circ} \mathrm{C}$ threshold was selected to account for partially frozen conditions as well as the scale mismatch between the temperature and LSM measurements. These data have thus to be interpreted with care, especially regarding their absolute values.

\section{Results}

\subsection{Sensor comparison and consistency}

At $30 \mathrm{~cm}$ depth two SMT100 sensors have been installed in parallel to investigate potential instrumental drift over longer time periods. Comparing their outputs also allows us to assess the quality of the sensor installation, the reliability of the measurements and potential spatial heterogeneity.

At FRE, DRE, MLS and GFU the correlation between the LSM measured by the two sensors is found to be satisfactory (lowest correlation at MLS: $r^{2}=0.766$, Fig. 4). The RMSE is more variable with the lowest value at GFU ( $2.19 \%$ vol) and the largest at DRE $(15.2 \% \mathrm{vol})$. Deviations from the one-to-one correspondence of the two sensors (black line in Fig. 4) can be attributed to small-scale soil heterogeneities 

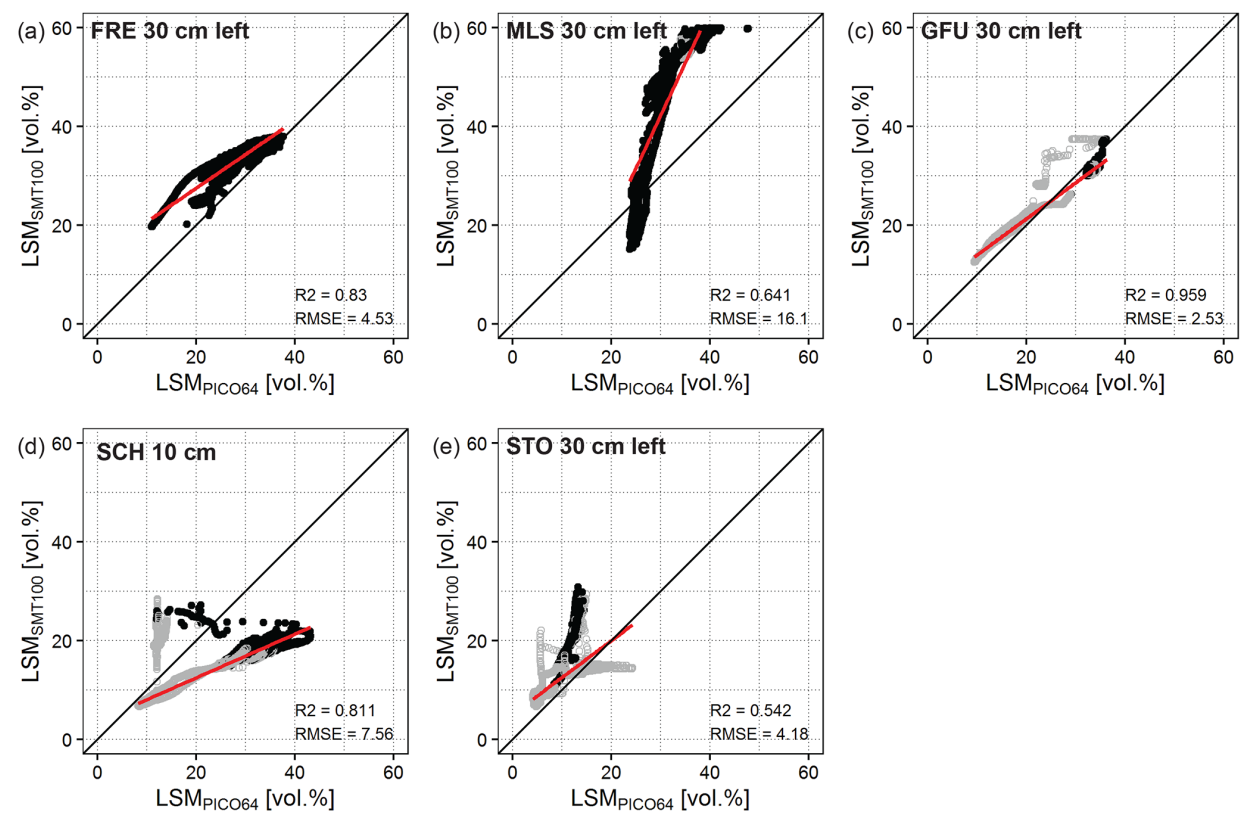

Figure 5. Comparison between PICO64-measured ( $x$ axis) and SMT100-measured LSM ( $y$ axis) at all sites. The linear relation is used for the SMT100 calibration. The hollow grey points at GFU, SCH and STO represent measurements taken when the ground temperature was below $1{ }^{\circ} \mathrm{C}$.

surrounding the sensors. Soil heterogeneities can result in differences of reaction time to infiltration and/or evaporation events as well as wet or dry biases due to different soil properties. This is particularly visible at MLS, where an increase of LSM is systematically recorded first by the left sensor ( $y$ axis) and later by the right sensor ( $x$ axis). At DRE (Fig. 4b) the right sensor shows consistently higher values $(\sim 5-10 \%$ vol $)$ than the left sensor, but the relation between the measured LSM values is almost constant, illustrating the effect of different soil properties.

$\mathrm{DRE}$ is also the site with the largest RMSE $\left(0.563^{\circ} \mathrm{C}\right)$ between the measured temperatures at $30 \mathrm{~cm}$ depth, indicating that specific physical processes such as convective heat transport through airflow within the coarse blocks of the ground (e.g. Wicky and Hauck, 2017) may influence the two sensors in a different way (see Sect. 5.3). At FRE, MLS and GFU the measured temperatures correspond almost perfectly one-toone showing no different physical processes. Therefore, the LSM deviations are most likely due to soil heterogeneities.

Sensor comparison was only possible at four sites. At $\mathrm{SCH}$ the terrain prevented the installation of two sensors at $30 \mathrm{~cm}$, whereas at STO one of the installed sensors gives unreliable data. This sensor probably suffers from bad coupling with the soil (air pockets near the blade and thus bad contact with the soil) stemming from a faulty installation due to the blocky subsurface.

In addition, the TDR-based PICO64 sensors, having a nominally higher absolute accuracy (Mittelbach et al., 2012), have been installed at $30 \mathrm{~cm}$ depth. Similar to Fig. 4, the comparison between SMT100 and PICO64 sensors at the same depth shows a generally good correlation (lowest $r^{2}=0.542$ at STO) with some deviations from the one-to-one relation (Fig. 5). The RMSE is generally larger than for the SMT100 intercomparison (Fig. 4) at all sites, which can be explained by the different measurement volume of the SMT100 and PICO64 sensors (see Sect. 2.1 and Fig. 2). At FRE and GFU the comparison between PICO64 and SMT100 LSM measurements yields very similar results to the comparison of the two SMT100 sensors, with slightly higher RMSE values (4.53 and $2.53 \%$ vol, respectively). MLS shows a larger dynamic range and mostly higher values for the SMT100 sensor $(\mathrm{RMSE}=16.1 \% \mathrm{vol})$, but a similar temporal variability $\left(r^{2}=0.641\right)$. A similar pattern is observed, when comparing the PICO64 sensor with the second SMT100 sensor installed at $30 \mathrm{~cm}$ (Table 5). This dry bias of the PICO64 sensor at MLS is probably due to a bad contact between its rods and the surrounding soil. At SCH and STO the differences between the sensors have a characteristic shape, but are centred on the one-to-one relation. It can be attributed to different onset of freezing and thawing at the two sensor locations (see also Fig. 6e-f). In addition, clear wet and dry biases in the PICO64 measurements are observed at SCH and STO, respectively, which can be explained by an unreliable calibration using Topp's equation for the high-mountain subsurface material present at SCH and STO (e.g. Robinson, 2004).

Figure 5 only considers the sensors at $30 \mathrm{~cm}$ (left) at all sites with the exception of $\mathrm{SCH}$, where the $10 \mathrm{~cm}$ sensor is used, since it is the depth of the only available PICO64. The same analysis was performed with the $30 \mathrm{~cm}$ right and $50 \mathrm{~cm}$ sensors (Table 5). The overall results are very similar regard- 

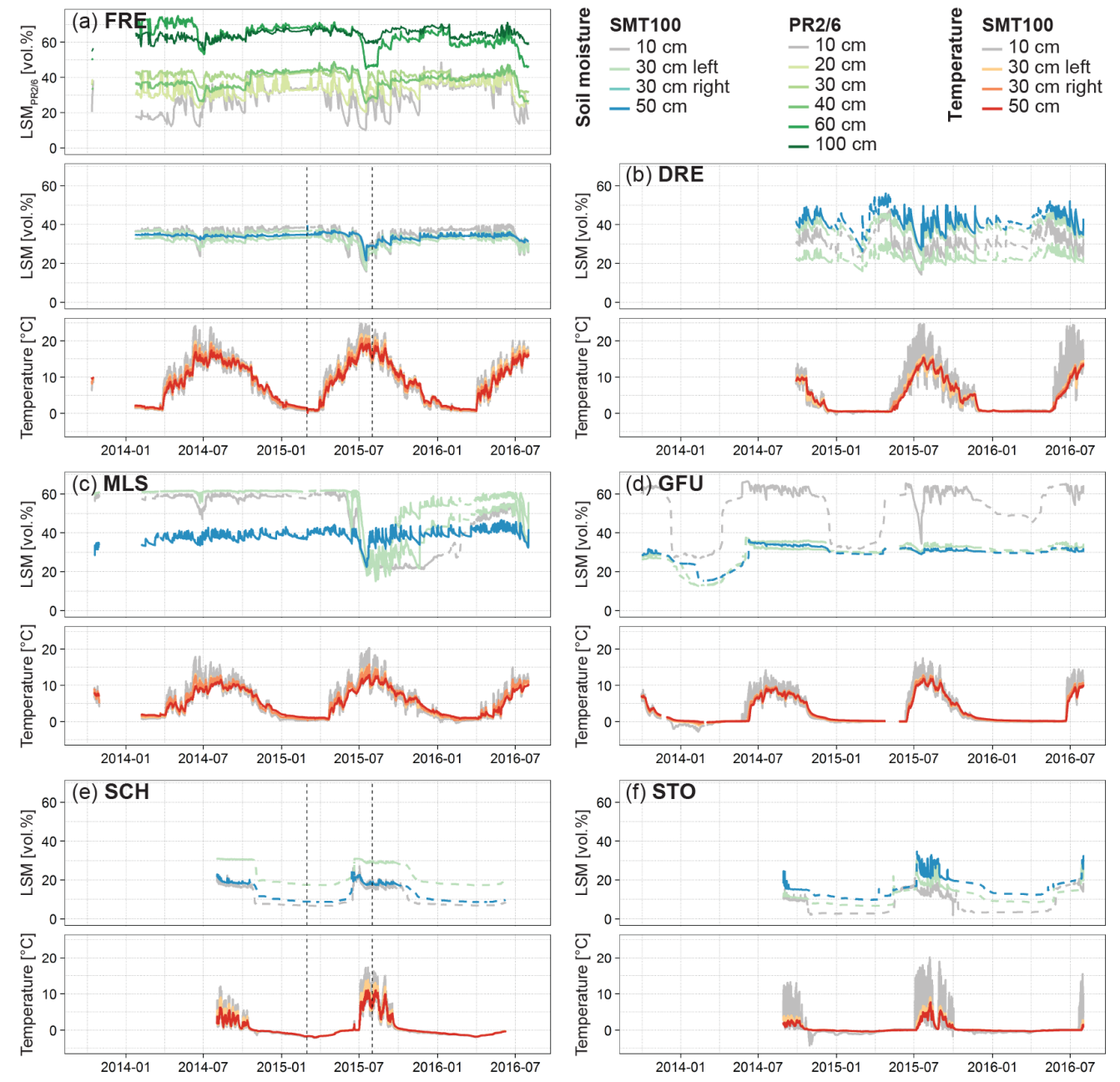

Figure 6. SMT100 measured LSM (upper panel) and ground temperatures (lower panel) at each SOMOMOUNT station (a-f). At FRE the uppermost panel displays the PR2/6 measured LSM. The vertical dotted lines at FRE and SCH indicate the period analysed in Fig. 7. The dashed LSM lines represent the soil moisture measurements taken when the ground temperature was below $1{ }^{\circ} \mathrm{C}$.

Table 5. Correlation $\left(r^{2}\right)$ and RMSE between the PICO64 and SMT100 measured LSM at all sites.

\begin{tabular}{lrr|rr|rr|r|r}
\hline Site & \multicolumn{2}{c|}{$10 \mathrm{~cm}$} & \multicolumn{2}{c|}{$30 \mathrm{~cm}$ left } & \multicolumn{2}{|c|}{$30 \mathrm{~cm}$ right } & \multicolumn{2}{c}{$50 \mathrm{~cm}$} \\
\cline { 2 - 9 } & $r^{2}$ & RMSE [vol.\%] & $r^{2}$ & RMSE [vol.\%] & $r^{2}$ & RMSE [vol.\%] & $r^{2}$ & RMSE [vol.\%] \\
\hline FRE & - & - & 0.830 & 4.53 & 0.934 & 2.12 & 0.504 & 10.4 \\
MLS & - & - & 0.641 & 16.1 & 0.848 & 12.1 & 0.553 & 10.1 \\
GFU & - & - & 0.959 & 2.53 & 0.890 & 2.37 & 0.910 & 1.78 \\
SCH & 0.811 & 7.56 & - & - & - & - & - & - \\
STO & - & - & 0.542 & 4.18 & - & - & 0.807 & 6.93 \\
\hline
\end{tabular}

ing statistical fit (lowest fit at MLS and highest fit at GFU) and observed patterns (not shown).

\subsection{Soil moisture temporal evolution}

Figure 6 shows the evolution of LSM and ground temperature at all SOMOMOUNT stations from July 2013 until Au- gust 2016. The temperatures exhibit a typical seasonal pattern with maximum values during the summer and minimum values in winter. The amplitude of these seasonal variations is specific to each site. DRE, GFU, SCH and STO exhibit temperatures close to and below the freezing point during the winter, whereas no freezing was recorded at FRE. At MLS 

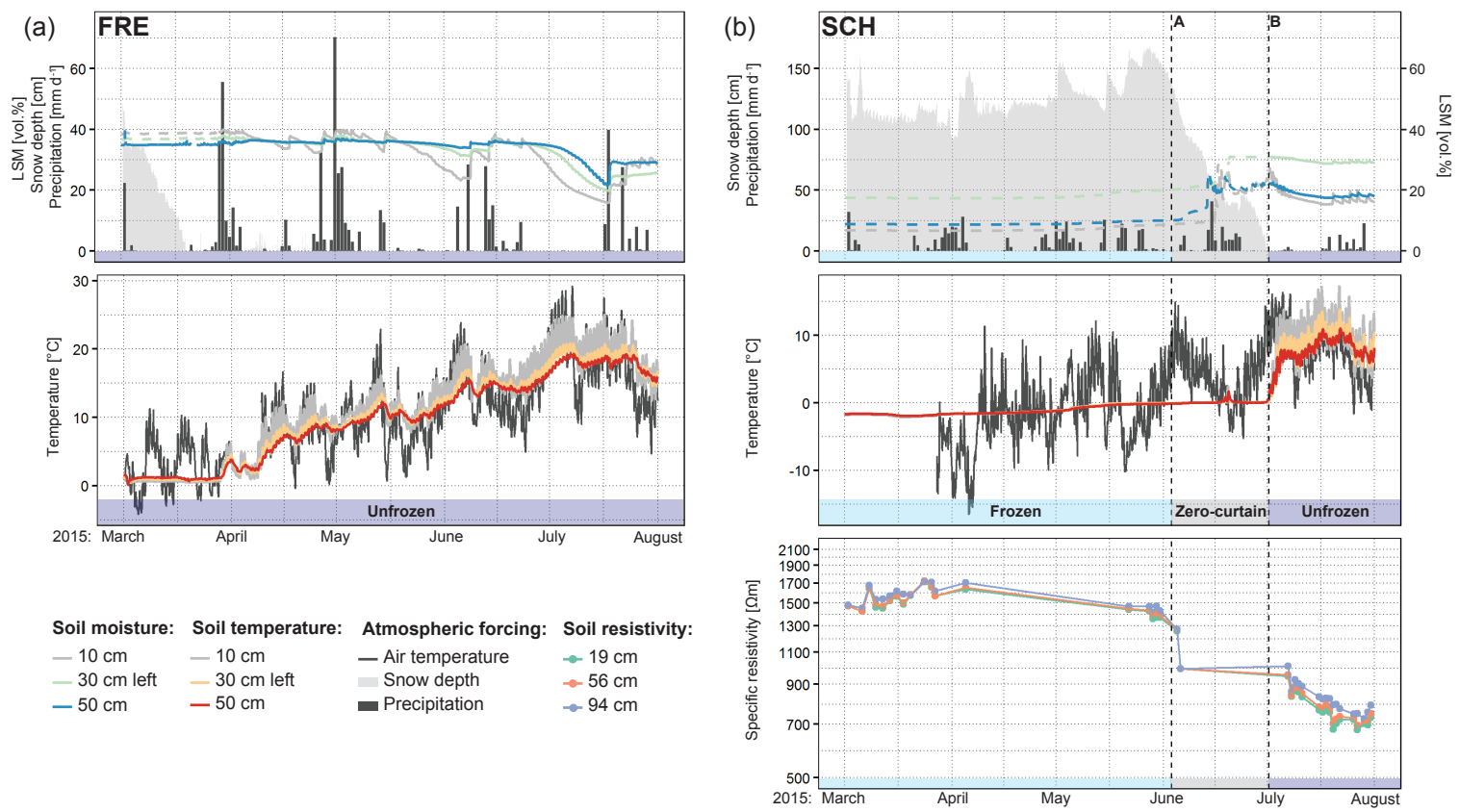

Figure 7. SMT100 measured LSM, ground temperature and soil resistivity at FRE (a) and SCH (b) from March to August 2015. In addition, daily air temperature, snow depth and precipitation sums are shown as well as the date of the transition between the different stages in the thermal evolution at $\mathrm{SCH}$ at $10 \mathrm{~cm}$ (dashed lines A and B; see text for details). The dashed LSM lines represent the soil moisture measurements taken when the ground temperature was below $1^{\circ} \mathrm{C}$.

negative soil temperatures were only observed at $10 \mathrm{~cm}$ depth during 10 days in early winter 2016.

On the other hand, the LSM differs strongly at each station and no common pattern is found. The sites can be divided into two categories of LSM dynamics: a low-elevation pattern at FRE and MLS characterized by a summer minimum of short duration and high LSM values for the rest of the year. The second category, typical for high elevations $(\mathrm{SCH}$ and STO), is defined by a long-lasting LSM minimum in winter, and maximum absolute values accompanied by strong variability during the summer. GFU and DRE display features characteristic from both categories, namely a long winter minimum as well as LSM decrease during summer. At GFU the $10 \mathrm{~cm}$ sensor values are much more variable than the values at 30 and $50 \mathrm{~cm}$ and exhibit higher values. This is due to the high organic content and low bulk density of this particular soil layer (Fig. 3d and Table 3).

Comparing the two summer seasons in 2014 and 2015 at FRE, MLS and GFU, one can observe a stronger LSM decrease in 2015 at all sites. This marked LSM decrease is due to the exceptionally high air temperatures and low precipitation recorded in July 2015 (MeteoSwiss, 2016; Scherrer et al., 2016), leading to increased evaporation. However, the effect of this anomalous event on LSM is different at all sites. At MLS the effect is the most pronounced ( $44 \% \mathrm{vol} \mathrm{LSM}$ loss at $30 \mathrm{~cm}$ ) and the LSM in the uppermost layers have still not returned to their original values in May 2016. At FRE the effect is less marked (18\%vol LSM loss at $30 \mathrm{~cm})$ and shorter but it can be observed down to $100 \mathrm{~cm}$. At DRE a drying is seen at all depths with a similar amplitude (12\%vol LSM loss at $30 \mathrm{~cm}$ ), whereas at GFU the effect is strong but of short duration at $10 \mathrm{~cm}$ (40\%vol LSM loss) and almost not seen below. Finally, at the two highest stations ( $\mathrm{SCH}$ and STO) no characteristic LSM decrease is observed.

To characterize these two patterns of LSM dynamics identified above in more detail and to analyse the processes controlling them, we focus on a 5-month period from spring to summer 2015 at FRE and SCH (Fig. 7).

At FRE the minimum LSM is reached during the summer, when air temperatures are highest and thus evaporation is maximal. No clear LSM maximum can be identified throughout the year (Fig. 6a) but multiple maxima are observed following precipitation events. The snow cover, which disappeared mid-March in 2015, reduces the link between LSM variations and atmospheric conditions. During the snowmelt period only a small LSM increase is seen, which could be attributed to conditions close to saturation throughout the winter. After the disappearance of the snow cover the variability of LSM increases at all depths and is systematically related to precipitation events (LSM increase) and dry spells, both, with and without air temperature increases (LSM decrease). As expected, the uppermost layer $(10 \mathrm{~cm})$ reacts stronger to atmospheric forcing than layers below. However, the response time is very fast and in some cases almost simultaneous at all depths, which is an indication for preferential flow. 
At $\mathrm{SCH}$ the evolution is very different. Minimum LSM values are recorded in winter, when the ground is entirely frozen and the maximum is reached in early summer due to the combined effect of snowmelt and thawing of the ground (Figs. 6f, 7b). As long as ground temperatures are below the freezing point, the meltwater from the snow cover is either running off directly at the surface or refreezes at the top of the frozen layer (and releases latent heat which can contribute to further thawing; e.g. Scherler et al., 2010). In contrast to FRE (Fig. 7a), the evolution of LSM at SCH is mainly driven by ground temperatures and the snow conditions and it is less affected by liquid precipitation. Three main stages of LSM evolution and ground thermal regime can be identified. The frozen stage is characterized by the lowest LSM values due to the frozen state of the ground and the insulating snow cover. It is followed by the zero-curtain period, defined by Outcalt et al. (1990) as extended period of time with near $0^{\circ} \mathrm{C}$ temperature induced by latent heat effects in a thawing or refreezing active layer. During this period LSM increases/decreases slowly but remains decoupled from precipitation events. Punctual lateral inflow and/or snowmelt water infiltration are possible (see Hilbich et al., 2011). Finally, the unfrozen stage coincides with the snow-free period and is characterized by high LSM variability coupled with the precipitation events. Although, the accuracy of the LSM measurements during the frozen and zero-curtain periods is difficult to assess due to the presence of ice, the relative changes, and thus the timing of each phase, are well captured. The LSM variations are coherent with the change of specific resistivity in the uppermost $\sim 50 \mathrm{~cm}$ of the ground. Similar to the dielectric permittivity, the electrical resistivity is highly dependent on the amount of unfrozen water content in the ground (Hauck, 2002). The frozen stage is thus characterized by high resistivities and a marked drop is observed during the zero-curtain period due to the thawing of the ground (see also Hilbich et al., 2011). Finally, the unfrozen stage exhibits the lowest resistivity values. The same typical stages of LSM evolution have been described for other mountain permafrost sites (e.g. Pellet et al., 2016) and landforms (e.g. Zhou et al., 2015). These stages are also observed in the data collected by spatially distributed SMT100 sensors installed at $30 \mathrm{~cm}$ depth at SCH and STO, with marked differences in absolute LSM as well as variable onset and duration of the three stages even at close vicinity (not shown).

\section{Discussion}

\subsection{Dominant processes}

To visualize how the moisture is transported through the ground we adapted the thermal orbits (Beltrami, 1996) to LSM (moisture orbits). It consists of a scatter plot of simultaneously measured LSM at two different depths. The shape of the resulting point cloud depends on the nature and speed of the vertical transport of water through the soil layers, as well as on soil properties such as hydraulic conductivity, degree of saturation and porosity. Using moisture orbits of different timescales (annual, pluri-annual and event), allows us to analyse the dominant processes for the temporal evolution of LSM.

\subsubsection{Seasonal variations}

To investigate the seasonal dynamic of LSM, we used moisture orbits between the SMT100 sensors installed at 10 and $50 \mathrm{~cm}$ depth for the year 2015 at each site (Fig. 8). Again, the field sites can be divided in two categories of LSM dynamics, controlled by different processes.

FRE and MLS exhibit similar moisture orbit shapes driven by precipitation events and evaporation. They are divided into three main stages. From January to May the LSM is maximal at both sensors, with some small variations due to snowmelt and/or precipitation events. Starting in June, the summer evaporation causes the LSM to decrease strongly at $10 \mathrm{~cm}$ and slightly at $50 \mathrm{~cm}$. Then LSM simultaneously decreases at both depths due to the increased evaporation generated by the July 2015 heat wave. Finally, LSM increases again, with different speed at each depth. The main difference between the two stations is that at MLS the orbit is not closed. At the end of 2015 there is about $30 \%$ vol LSM less than at the beginning of the year. It indicates that at MLS the near-surface LSM did not recover from the increased evaporation generated by the heat wave in July 2015 (see Fig. 6). The dry top soil conditions can generate a large water potential gradient with depth and thereby an increased infiltration capacity, but also suitable conditions for potential preferential flow processes, which tend to induce bypass flow of precipitation water (e.g. Wiekenkamp et al., 2016). On the contrary, at FRE the LSM returned to its original value. Both sites received a similar amount of precipitation following the heat wave, from July to end of 2015 (443 and $534 \mathrm{~mm}$, respectively, MeteoSwiss). Furthermore, the atmospheric forcing (i.e. air temperature, radiation and calculated potential evaporation) was very similar as well (MeteoSwiss). Therefore, the larger and longer-lasting impact of the 2015 heat wave at MLS is due to the higher initial LSM and thus lower potential evaporation limitation than at FRE. The amount of available water for evaporation is dependent on the soil properties. At MLS the soil type is silty loam and is able to retain more water than the sandy loam present at FRE.

At SCH and STO the shape of the moisture orbit is controlled by freezing/thawing processes. It can be divided into five stages consistent with the frozen, zero-curtain and unfrozen state of the ground. At the beginning of the year both sensors show their lowest value (frozen stage). This is followed by a sharp increase at $50 \mathrm{~cm}$ not seen at $10 \mathrm{~cm}(1)$ and a strong increase at $10 \mathrm{~cm}$ but not at $50 \mathrm{~cm}$ (2) consistent with the melting of the ground from underneath, which takes place at different times at the two depths (spring zero cur- 

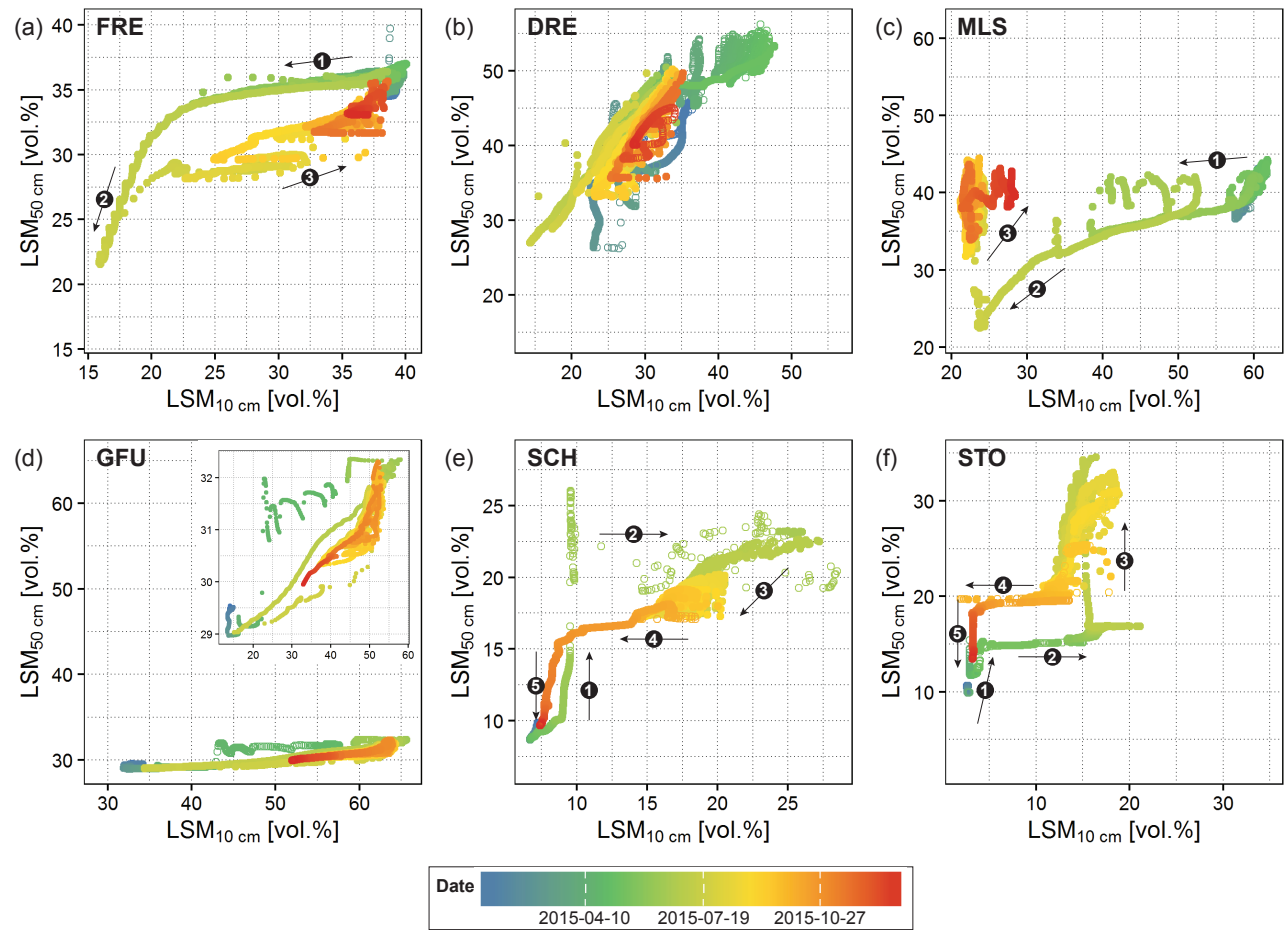

Figure 8. Moisture orbit at each SOMOMOUNT station from the 1 January to the 31 December 2015. The numbered arrows indicate the most important stages at each station as well as the sense of the evolution. The hollow circles represent LSM measurements taken when the temperature was below $1^{\circ} \mathrm{C}$ at $10 \mathrm{~cm}$.

tain). The start of the thawing process at larger depth can be due to preferential water infiltration events or to the influence of high temperatures from the preceding summer (e.g. Zenklusen Mutter and Phillips, 2012). In the latter case, the ground temperatures in spring are higher at depth compared to the near surface due to the time lag of heat propagation into the subsurface. The occurrence of this phenomenon depends on the thermal properties of the subsurface and the strength of the winter freezing. Although the thawing process systematically starts at the surface in response to meteorological forcing, the heat reservoir remaining at larger depth can also start the thawing from below. This process is more likely to occur where the permafrost temperatures are close to $0^{\circ} \mathrm{C}$ as it is the case at SCH. During the summer, the ground is unfrozen and strong variations are recorded at both depths (3). The orbit is finally closed by a succession of LSM decrease at $10 \mathrm{~cm}$ not seen at $50 \mathrm{~cm}(4)$ and a strong decrease at $50 \mathrm{~cm}$ but not $10 \mathrm{~cm}(5)$, consistent with the downward propagation of the freezing front from the surface (autumn zero curtain). The orbits are closed at both sites indicating no long-lasting perturbation during the year 2015 as well as similar winter conditions. These stages have also been observed by, e.g., Hilbich et al. (2011) and Zhou et al. (2015).

At DRE and GFU it is difficult to determine a clear temporal evolution of LSM. DRE exhibits a winter and summer minimum (see also Fig. 6b) corresponding to the freezing of the ground and the summer evaporation peak, respectively.
This double minimum is also found at GFU but less marked, especially at the deeper layer.

\subsubsection{Soil type dependency}

At DRE the shape of the moisture orbit is almost diagonal indicating very rapid transfer of water from the surface downward and little storage in the uppermost soil layer (wet anomaly at $50 \mathrm{~cm}$ ). This is due to the soil properties. At DRE the soil profile down to $50 \mathrm{~cm}$ consists of one single organicrich sandy loam layer with a very low bulk density (Table 3), which is underlain by large sized boulders. These particular soil properties render the uppermost layer highly draining (Beringer et al., 2001) and the water is rapidly transported through. The boulders underneath do not retain the water, likely preventing the creation of any shallow water table. Furthermore, and in contrast to the large blocks below, the organic-rich material at the surface retains the water and has a larger thermal conductivity (Beringer et al., 2001), thus favouring summer evaporation and winter freezing.

At GFU the presence of an organic-rich layer in the uppermost $10 \mathrm{~cm}$ of the soil causes the measured LSM at $10 \mathrm{~cm}$ to be highly variable and generally higher than in the remaining soil column (see also Fig. 6d). At $50 \mathrm{~cm}$ the measured LSM shows near-saturation conditions throughout the year indicating a potential influence of shallow groundwater. This is confirmed by additional ERT measurements realized in summer 
from 2013 to 2015, which indicate extremely low specific resistivities $(\sim 250 \Omega \mathrm{m}$ ) down to $2.5 \mathrm{~m}$ (not shown). The combination of these two factors explains the almost horizontal moisture orbit shape observed at GFU. The organic-rich layer has a lower thermal conductivity (Beringer et al., 2001) than the other soil types, thus reducing the influence of air temperature (evaporation and/or freezing) at larger depth. Furthermore, at 30 and $50 \mathrm{~cm}$ the soil is composed of loam and sandy loam with much larger bulk densities (Table 3), which are typically characterized by lower hydraulic conductivities if no preferential flow is occurring (Cosby et al., 1984). These soil properties also contribute to the observed lower LSM variability at these depths.

At FRE and MLS, the soil type is relatively homogeneous within the uppermost $50 \mathrm{~cm}$ of the ground, which results in similar LSM temporal evolution with only slight variations in timing and absolute values between the sensors. At MLS the soil type is silty loam and is thus able to retain more water than the sandy loam present at FRE. Finally at SCH and STO, the ground consists of sand or loamy sand, with a significant proportion of soil particles larger than $10 \mathrm{~mm}(25$ and $45 \%$, respectively, at $10 \mathrm{~cm}$; see also Fig. 3e-f). Such soil composition is highly heterogeneous even over small distances explaining the high variability between the sensors as well as the comparatively low LSM during unfrozen and snow-free periods.

\subsubsection{Climate dependency}

As seen in Fig. 6, the LSM temporal evolution is strongly influenced by the variations in atmospheric conditions such as the heat wave of July 2015. Thus, the shapes of the moisture orbits can be different for each year even though the same processes are dominant (evaporation or freezing). Comparing all years where measurements are available (Fig. 9), one can see that at low elevation (FRE), where the evolution of LSM is mainly controlled by evaporation and precipitation, the moisture orbits of the year 2014 and 2016 are very similar in shape and amplitude, whereas 2015 is marked by an exceptional decrease of LSM at both depths.

Conversely, at high elevation in permafrost terrain $(\mathrm{SCH})$, 2015 is not particularly anomalous and the same patterns with comparable amplitudes are observed in all years available. This is to be expected since the freezing/thawing processes occur every year, with only slight variations regarding snow duration and timing.

Finally, at GFU, which is an intermediate site with similar characteristics to both FRE and $\mathrm{SCH}$, two very different orbit shapes can be observed. In 2014, the ground froze down to $50 \mathrm{~cm}$ producing a moisture orbit similar to $\mathrm{SCH}$ and STO characterized by large variations occurring at the two sensors. Conversely, in 2015 and 2016 only the $10 \mathrm{~cm}$ layer froze, yielding horizontal shaped moisture orbits.

\subsubsection{Infiltration events}

Using differential moisture orbits one can also characterize single infiltration events and investigate further the influence of the soil type on the short-term LSM evolution. We selected one precipitation event recorded at all six stations and plotted the moisture orbits for a period of 5 days (Fig. 10). At all sites except STO, this precipitation event yields clear moisture orbits of different shapes and amplitudes. The slope of the orbits indicates at which depth the LSM is most affected by the precipitation event and the amount of infiltrating water.

At FRE, GFU and SCH the orbits are horizontal (SCH) to slightly inclined (FRE and GFU), showing that the strongest variations of LSM are occurring at $10 \mathrm{~cm}$. The wetting and drying phases are faster and the perturbation is larger at $10 \mathrm{~cm}$ than at $50 \mathrm{~cm}$. At SCH the maximum LSM at $10 \mathrm{~cm}$ is reached after $2 \mathrm{~h}$ while no variation is recorded at $50 \mathrm{~cm}$ during that interval. The LSM starts increasing at $50 \mathrm{~cm}$ once the LSM at $10 \mathrm{~cm}$ is already decreasing. This pattern is consistent with the vertical succession of soil material found at SCH: sandy loam near the soil surface, which retains water at the beginning of the event and sand at larger depth, which is more draining. At FRE and GFU the orbits correspond to soils with smaller hydraulic conductivity and higher retention capacity (sandy loam and loam-sandy loam, respectively, Table 3).

At DRE the moisture orbit has a large amplitude at both depths with a slope $>45^{\circ}$. It indicates a rapid transfer of water through the soil and little storage at $10 \mathrm{~cm}$, which is typical for the particular soil composition found at DRE (single organic-rich layer with low bulk density underlain by coarse blocks with large interconnected pores).

At MLS the moisture orbit is almost vertical due to LSM increase/decrease at $50 \mathrm{~cm}$ depth only, which indicates an instantaneous transfer of water through the uppermost layer. It is the station where the event was the smallest $\left(+8 \mathrm{~mm} \mathrm{~d}^{-1}\right)$ but the resulting perturbation was the second highest $(>+7 \%$ vol). From Fig. $6 c$, it can be seen that, at the time of the precipitation event, the LSM at 10 and $30 \mathrm{~cm}$ depths were unusually low (23 and $24.5 \%$ vol, respectively), thus generating a larger gradient in pressure head from the surface to the lower soil layers as well as providing very suitable conditions for the activation of preferential flow (see, e.g., Wiekenkamp et al., 2016). The degree of saturation of the soil layer is thus another key factor influencing the LSM dynamics. The almost total absence of LSM variation at $10 \mathrm{~cm}$ during this infiltration event could also indicate lateral flow of water.

Our interpretation of the moisture orbit shapes accounts only for vertical transfer of water in the soil. However, lateral flows can also play an important role. At DRE, MLS, SCH and STO the stations are located on slightly inclined slopes or at their bottom. Furthermore, permanent snow patches have been observed at SCH and STO on several occasions and 

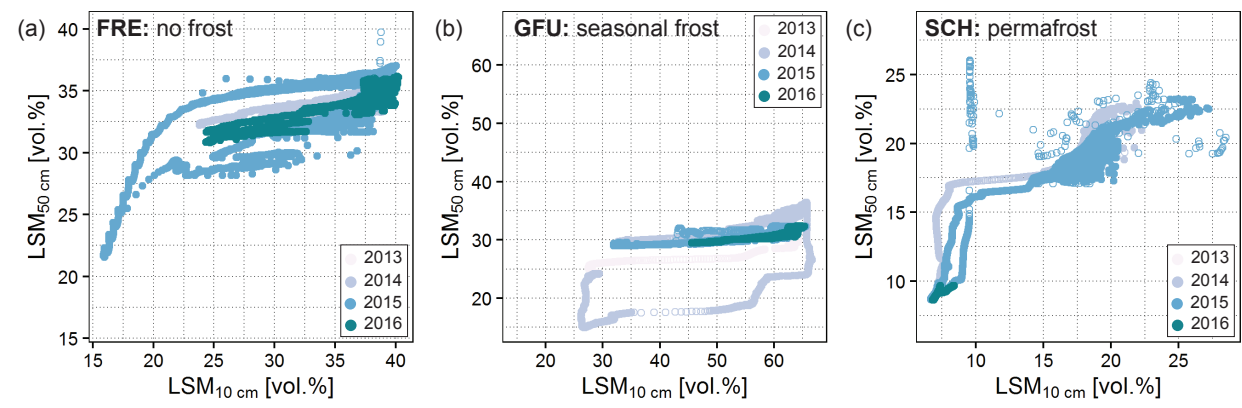

Figure 9. Moisture orbits at FRE (a), GFU (b) and SCH (c) for the consecutive monitoring years (January 2014-August 2016 at FRE, August 2013-August 2016 at GFU and August 2014-June 2016 at SCH). The hollow circles represent LSM measurements taken when the temperature was below $1^{\circ} \mathrm{C}$ at $10 \mathrm{~cm}$.
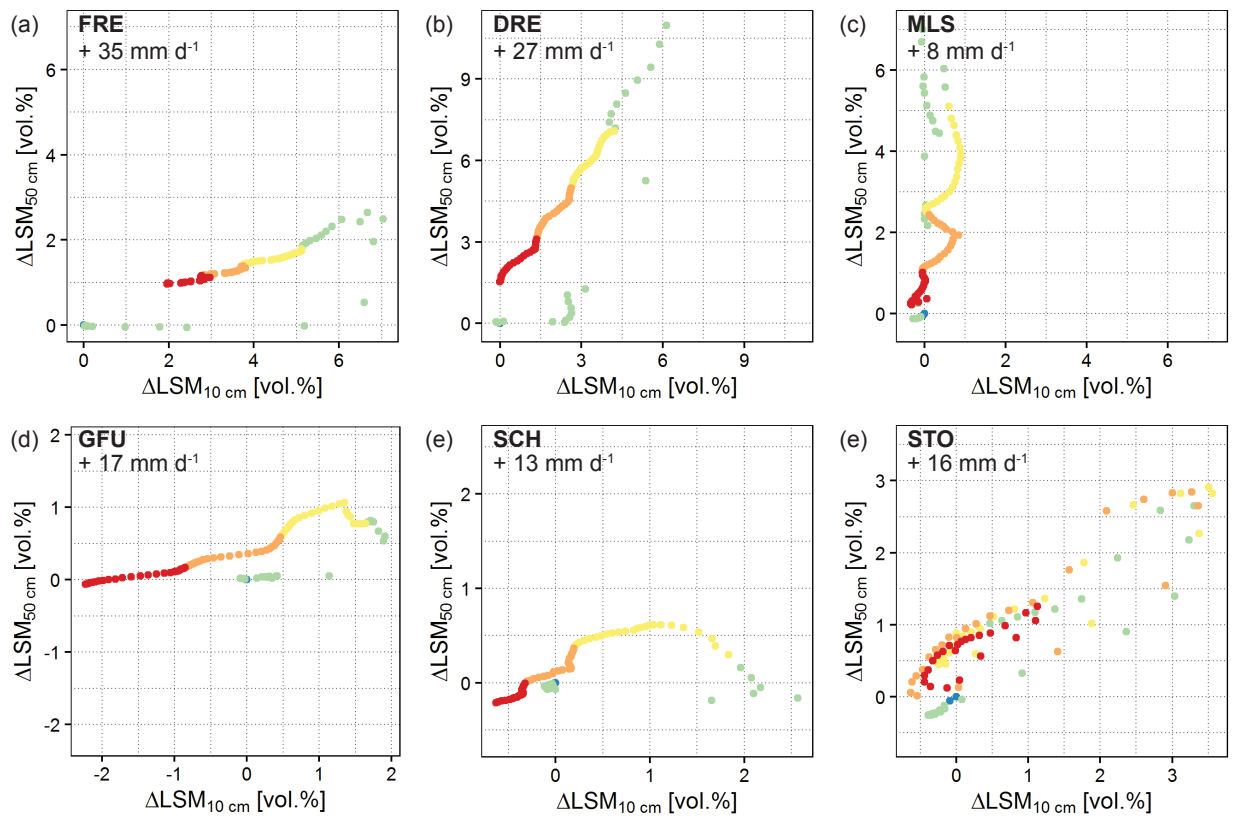

$2015-08-23 \quad 2015-08-24 \quad 2015-08-25$ ○ $2015-08-26$

2015-08-27

Figure 10. Moisture orbit at each SOMOMOUNT station for one precipitation event between the 23 and the 27 August 2015 . The LSM values are given as hourly mean and expressed as the change of absolute value compared to the first measurement (23 August at 23:00). The daily precipitation sums recorded (FRE, DRE and MLS) and extrapolated (GFU, SCH and STO) for the 24 August are indicated.

may constitute a continuous water supply during summer (Python, 2015; Wicki, 2015). The infiltration of snowmelt water is a spatially very heterogeneous process on slopes, especially when the subsurface is characterized by large size particles and draining soil types. An example of the influence of snowmelt processes can be seen at STO, where the precipitation event shown in Fig. 10e did not yield a clear moisture orbit. Its effect is lost in the daily moisture orbit patterns due to snowmelt cycles. For each day shown in Fig. 10e, an oval shaped moisture orbit is present. These daily cycle orbits are very similar in amplitude and structure. The uppermost sensor reacts first (wetting and drying) and the maximum LSM increase happens at the same time at both depths.
As seen above for MLS, the influence of a single precipitation event on LSM depends not only on the soil properties but also on the moisture conditions prior to the event. To investigate this process we computed the moisture orbits of three selected precipitation events at FRE and DRE, which were preceded by different LSM conditions (Fig. 11). The first event in mid-May is a combination of low precipitation amount preceded by comparatively high LSM. The second event is of very different amplitude at both sites $\left(+39 \mathrm{~mm} \mathrm{~d}^{-1}\right.$ at FRE and $+10 \mathrm{~m} \mathrm{~d}^{-1}$ at DRE) but it marked the end of the summer 2015 heat wave at both sites. The last event is the same as in Fig. 10. It consists of a large amount of precipitation preceded by relatively high LSM. 

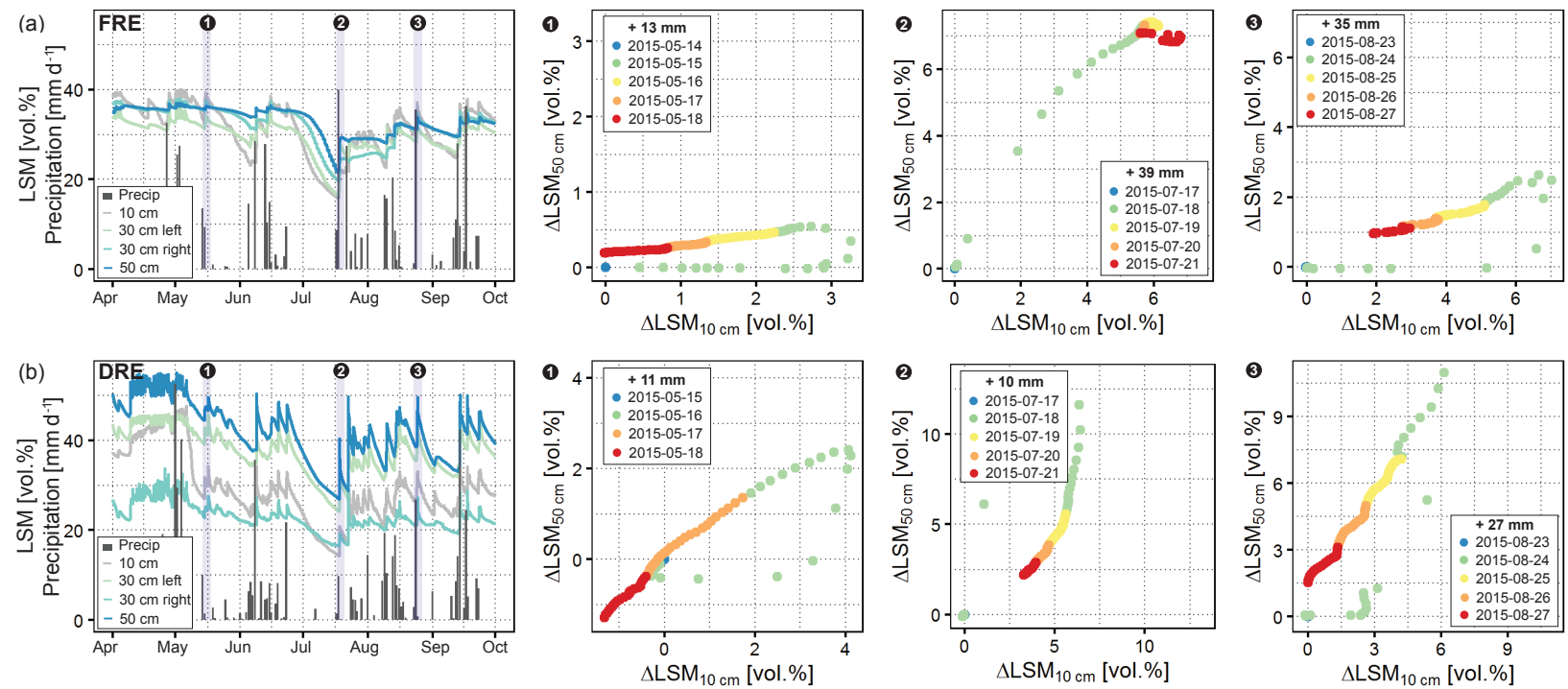

Figure 11. Moisture orbit at FRE (a) and DRE (b) for three precipitation events in 2015. The LSM values are hourly means and expressed as the change of absolute value compared to the first measurement (first day at 23:00). The daily precipitation sums recorded at the beginning of each event are indicated.

At FRE, the first and third events yield similar moisture orbit shapes with a larger amplitude for the larger precipitation event. However, the second event produces a diagonal moisture orbit with almost no LSM decrease. As for MLS above, the LSM is low at all depths creating suitable conditions for preferential flow as well as an increased infiltration capacity due to a high gradient of water potential. Both processes could explain the larger and faster increase of LSM observed at larger depth due to the bypass of the dry uppermost layer. The same indications for preferential flow are seen at DRE, where the second precipitation event is comparatively small $\left(+10 \mathrm{~mm} \mathrm{~d}^{-1}\right)$ but yields the strongest and fastest LSM increase at depth. Given the soil properties, the preferential flow interpretation is preferred to the enhanced infiltration capacity.

\subsection{Altitude dependency}

As seen above four main processes are driving the annual LSM dynamics, namely evaporation/infiltration and freezing/thawing of the ground. The respective predominance of one of these processes is dependent on the station location and more specifically on its elevation. Using all SOMOMOUNT stations as well as selected SwissSMEX stations (SIO, PAY and PLA) and Cervinia, we investigated the elevation dependency of mean annual and mean seasonal LSM for the year 2015 (Fig. 12a).

The relation between LSM and elevation is clearly nonlinear. Disregarding DRE (see Sect. 5.3), a distinct pattern emerges. The mean annual LSM regularly increases with elevation until about $2000 \mathrm{~m}$ a.s.l. and then decreases with increasing elevation. This tipping point corresponds also to a clear shift in the LSM regime. Below $2000 \mathrm{~m}$ a.s.l. the maximum LSM is recorded in winter and the minimum in summer, whereas above this threshold the inverse occurs (maximum LSM in summer and minimum in winter).

This shift in LSM regime can be related to a series of variables, which are known to be important for mountain climates and which have also been plotted against elevation (Fig. 12b-e). Air temperature (Fig. 12b) is one of the controlling factors for evaporation and freezing processes, whereas the precipitation amount (Fig. 12c) controls the water input at the surface. Snow cover duration (Fig. 12e) has several effects on the LSM dynamics: it insulates the ground from the cold winter temperatures (yielding positive surface offsets, i.e. the difference between ground and air temperature; Fig. 12b) and it acts as a water retention layer, which stores water throughout winter and liberates it in spring/early summer. For each variable, all available data from the monitoring networks of MeteoSwiss, PERMOS and IMIS (Intercantonal Measurement and Information System maintained by the SLF) were collected and a linear regression model was calculated based on the annual mean (resp. sum) of the year 2015. Globally, the same elevation dependency trends are observed using the single stations (dots) or the entire datasets (regression lines).

From Fig. 12 the following relationships can be determined: ground and air temperature, as well as the thawing degree days (absolute sum of positive temperatures per year) all linearly decrease with elevation, yielding a decreasing trend of evaporation and thus a theoretically increasing trend of LSM. Conversely, the freezing degree days (absolute sum of negative temperatures per year), surface offset and the snow cover duration increase with elevation, 

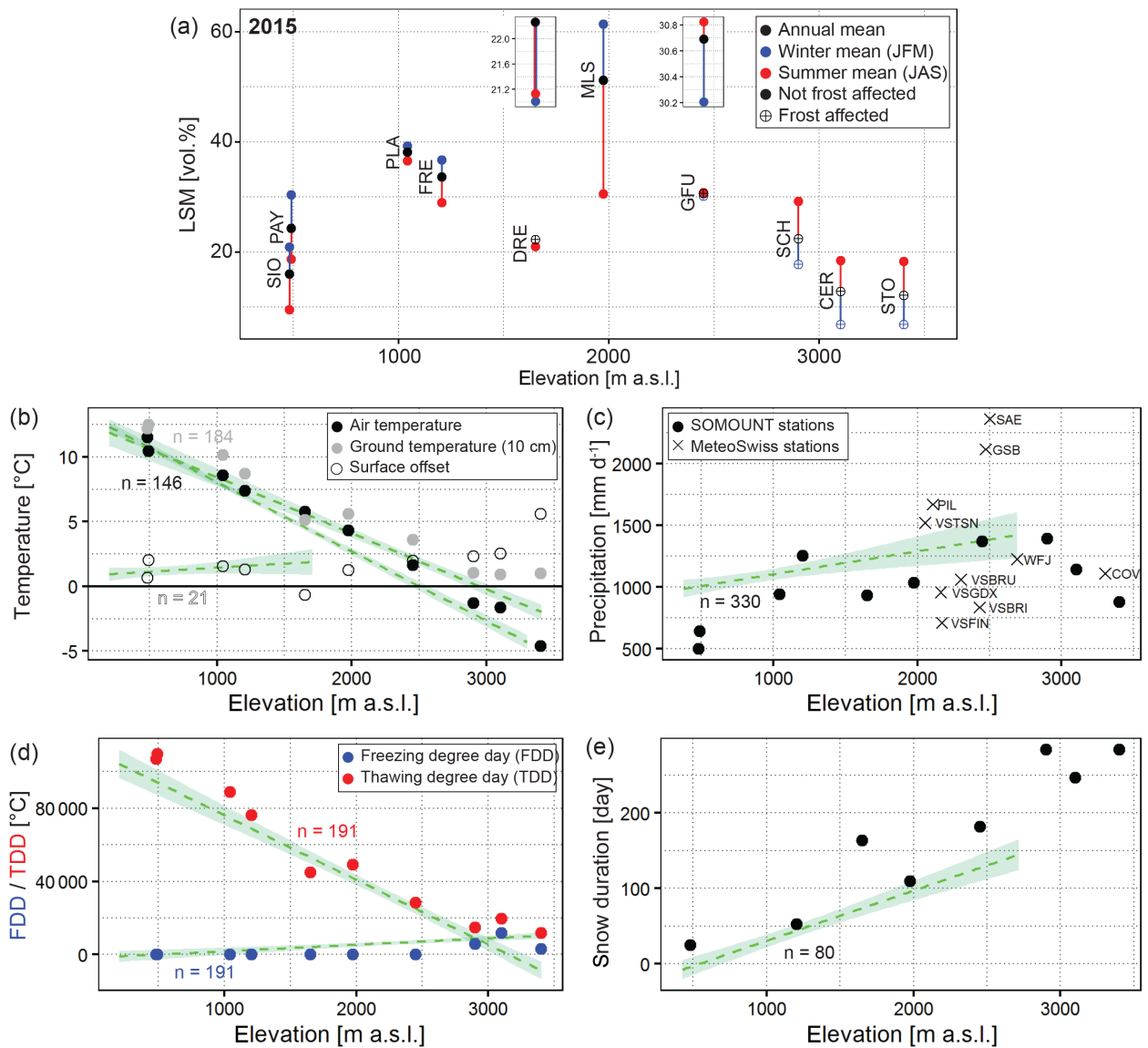

Figure 12. Elevation dependency of the winter, summer and annual mean LSM at $30 \mathrm{~cm}$ depth (a), air, ground temperature and surface offset (ground minus air temperature) at $10 \mathrm{~cm}$ (b), annual precipitation sum including selected SwissMetNet stations for comparison (see Fig. 1) (c), freezing and thawing degree days (calculated from ground temperatures at $10 \mathrm{~cm}$ ) (d) and snow duration (calculated from ground temperature at $10 \mathrm{~cm}$ using the method described in Staub and Delaloye, 2017) (e) during the year 2015. The LSM values for SIO, PAY and PLA are part of the SwissSMEX network (Mittelbach and Seneviratne, 2012). Due to missing data at $30 \mathrm{~cm}$, the LSM shown for PAY and PLA was measured at 50 and $20 \mathrm{~cm}$ at CER. The dashed green lines illustrate the linear regression based on all available SwissMetNet, PERMOS and IMIS stations in Switzerland (the numbers of station with complete data series in 2015 are indicated) and the shaded areas represent the $99 \%$ confidence intervals. The length of each regression line corresponds to the maximum elevation of the available stations.

which results in longer-lasting winter LSM minimum and thus lower mean annual LSM with increasing elevation. Finally, a slightly increasing trend in the precipitation distribution is observed with large site-specific variations due to the strong microclimatic effects; however, on larger spatial scale (continental) precipitation is known to increase with elevation (Smith, 1979). This combination of overall increasing precipitation and decreasing evaporation yields a trend of increasing LSM with elevation until the altitude threshold of about $2000 \mathrm{~m}$ a.s.l., where it is balanced by the increasingly important ground freezing. Above this threshold LSM starts decreasing with elevation.

At lower elevation (below $2000 \mathrm{~m}$ a.s.1.), evaporation dominates the LSM regime, causing the summer LSM minimum. With increasing elevation air temperature decreases, precipitation increases and the snow cover duration is prolonged, explaining the increase of mean annual LSM.
At higher elevation (above $2000 \mathrm{~m}$ a.s.l.), the ground thermal regime and more specifically the soil freezing process drives the LSM regime, causing the LSM minimum to shift from summer to winter, when freezing occurs. This is confirmed by the observed negative ground temperatures as well as the increasing freezing degree days. Air and ground temperatures decrease with increasing elevation yielding increasingly long duration of seasonally frozen ground and thus explaining the decreasing trend of LSM.

\subsection{Special case: Dreveneuse}

To summarize the findings from the SOMOMOUNT network presented above, a simple theoretical model of the distribution of LSM and its contributing factors with elevation can be visualized with the grey shading in Fig. 13. Comparing the observations qualitatively with this model (circles in Fig. 13), 


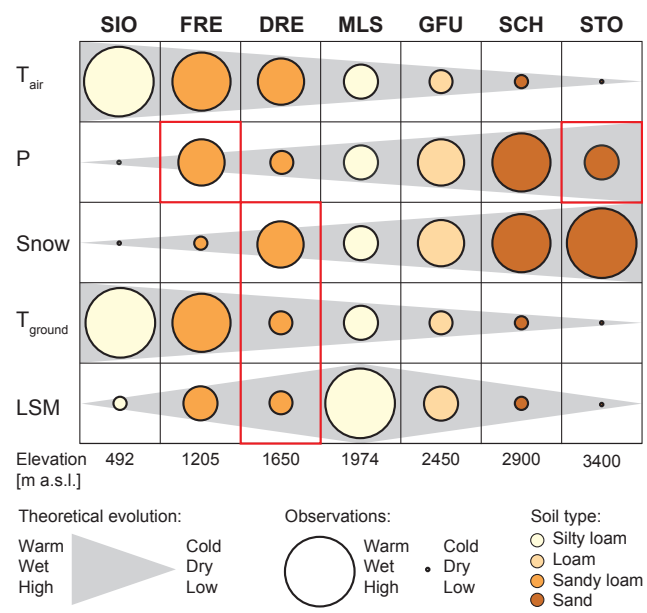

Figure 13. Generalized schematics of the evolution of air temperature, precipitation, snow duration, ground temperature and LSM with elevation. The circles represent the observations from 2015 (see Fig. 12), the grey area the expected theoretical evolution and the colour scale the soil type. The mismatches between model and observations are highlighted in red.

it can be seen that DRE does not fit the model. The recorded mean annual LSM values are much lower than expected. This is due to the composition of the soil profile, which is an elevation-independent factor. The uppermost layer of the subsurface has a very high porosity ( $>90 \%$, see Table 3 ), which leads to exfiltration of water into the underlying talus slope or lateral water transport. Furthermore, and conversely to FRE and MLS, no evidences of groundwater influence are seen at DRE (Fig. 6). This is consistent with the coarse blocky structure of the talus slope, which does not retain the infiltrating water.

The case of DRE is also particular in terms of snow duration (longer than expected) and mean annual ground temperature (lower than expected). Both anomalies are due to sitespecific characteristics, which are independent from elevation. The low mean annual ground temperature results from convective heat transport by a complex air circulation within the underlying talus slope (Delaloye, 2004; Morard, 2011), which is made possible by the large interconnected pore space between the coarse blocks of the talus. During winter, ascending warm air within the talus slope leads to cold air inflow at the bottom of the talus slope, where the soil moisture and weather stations are located. This process is able to efficiently cool the ground even when the snow cover is present. In summer the air circulation is reversed and a gravity-driven outflow of cold air from the inside of the talus slope takes place at the bottom, where LSM and ground temperatures are measured. This process has been observed at many similar talus slopes in low and high-elevation mountain regions (e.g. Delaloye and Lambiel, 2005; Gude et al., 2003; Kneisel et al., 2000; Sawada et al., 2003; Wakonigg, 1996). Furthermore, the lower ground temperatures caused by the air cir- culation have been successfully reproduced using numerical modelling (Wicky and Hauck, 2017). The longer snow duration is due to the spruces and low vegetation surrounding the station, which efficiently traps the snow for an extended period of time. The cold ground temperatures help in addition to conserve the snow cover for a longer period.

The relatively low elevation of DRE implies a high air temperature and thus more energy available for evapotranspiration. Additionally, the presence of vegetation at the surface induces water uptake. The reduced ground temperatures by the air circulation result in a negative surface offset (ground temperature lower than air temperature) and slightly positive freezing degree days, both indicating a seasonal freezing of the ground. Thus, two phases of minimal LSM values are observed: one during the summer due to evaporation and one in winter due to partial or complete freezing of the ground (see Figs. 6b, 12a).

The elevation-dependent generalized schematics shown in Fig. 13 have been empirically developed using seven stations. Although the stations are regularly distributed with elevation ( $\sim 500 \mathrm{~m}$ steps $)$ the representativeness of these locations is hard to assess. Additional low-elevation LSM monitoring stations are available within the SwissSMEX network and fit well in the presented model. Comparison with further low to middle altitude stations in the Black Forest region (south-western Germany) show also good agreement (Krauss et al., 2010). Finally, the high-elevation monitoring station at Cervinia, Italy ( $3100 \mathrm{~m}$ a.s.l., see Pellet et al., 2016), exhibits LSM dynamics comparable to STO and SCH and its mean annual LSM for 2015 fits well in the elevation model presented above.

However, the example of DRE shows that some of the processes and site-specific properties playing a role in LSM dynamics do not have a trivial elevation dependency. Precipitation in mountainous areas is especially difficult to monitor and the elevation factor is hereby less important than topographic effects. As shown in Fig. 12c, the annual sum of precipitation at a given altitude can vary up to $2000 \mathrm{~mm} \mathrm{yr}^{-1}$ depending on the location. From our field sites FRE appears to receive more precipitation than expected, whereas STO receives much less than predicted. Indeed, FRE is situated on top of the easternmost ridge of the Jura mountain chain, which is known to have a comparatively high annual precipitation sum, as is also shown by the neighbouring SwissMetNet stations of Chasseral (1599 m a.s.l.) and Chaumont (1136 m a.s.l.), which recorded annual precipitation sums of 1509 and $1240 \mathrm{~mm} \mathrm{yr}^{-1}$, respectively, for the period 19611990 (MeteoSwiss). STO is located in the central Alpine region, which is very dry due to the wind shading effect from the surrounding mountain crests (see, e.g., Smith, 1979). This effect is also seen at the station of Findelen (VSFIN), which is located about $3 \mathrm{~km}$ from STO and which is also much drier than the stations at comparable elevation (Fig. 12c). 


\section{Conclusion}

In this paper we presented a detailed description of the new soil moisture monitoring network for middle and high altitudes in Switzerland (SOMOMOUNT). Starting in summer 2013, six automatic stations have been set up along an elevation gradient ranging from 1205 to $3410 \mathrm{~m}$ a.s.l.

The use of two types of standard soil moisture sensors for application in coarse-grained terrain undergoing freeze/thaw cycles at middle and high elevation was shown to be reliable, both regarding inter-sensor comparisons as well as in comparison with related variables such as ground temperature and precipitation. A standard calibration approach combining in situ and laboratory analysis was applied to improve the measurement accuracy. However, the absolute value during the frozen period remains difficult to assess even though both the SMT100 and the PICO64 sensors yield similar absolute values ( $\pm 3 \%$ vol range). The measurements also confirmed that unfrozen water content is present at temperatures below the freezing point and that it can be measured with the sensors.

The data collected during the first 3 years of the SOMOMOUNT network revealed very distinct LSM dynamics at the different sites, which were summarized into a simple elevation-dependent model. At middle and low elevation, annual LSM dynamics is controlled by evapotranspiration and precipitation events, whereas at high elevation the freezethaw cycle is the main driving factor. This shift between the two distinct moisture regimes was found to take place at about $2000 \mathrm{~m}$ a.s.1., where the maximum annual LSM values have been recorded.

Marked inter-annual variations have been observed. However, depending on the site-specific properties, the impacts have been more or less important. The exceptionally high air temperatures of July 2015 induced a stronger and longer-lasting LSM decrease than 2014 or 2016, but only for low- and middle-altitude stations. At high elevation (> $2900 \mathrm{~m}$ a.s.1.) no effect of the 2015 heat wave was observed, since the LSM dynamics is predominantly controlled by the ground thermal regime.

Among the six SOMOMOUNT soil moisture stations, and also in comparison with additional stations from other networks, the station of Dreveneuse is a clear exception to the elevation-dependent theoretical model. The lower than expected LSM can be attributed to particular soil properties, which favour rapid water transport through the ground. In addition, this middle elevation site undergoes strong winter freezing as well as marked summer evaporation, the latter being due to the vegetation cover. Due to complex air circulation within the underlying talus slope, the ground temperatures are unusually low for this elevation. Finally, the soil properties were found to play an important role in the shortterm LSM variations as well as in the mitigation or intensification of the extreme events.
Data availability. The soil moisture data are stored at the Department of Geosciences and can be obtained through the corresponding author. The meteorological data of the different stations can be obtained upon request from the Swiss Federal Office of Meteorology and Climatology, MeteoSwiss or the PERMOS network (www.permos.ch).

Competing interests. The authors declare that they have no conflict of interest.

Acknowledgements. This study was conducted within the SOMOMOUNT project funded by the Swiss National Science Foundation (project no. 143325). All data from the SwissMetNet weather stations have been provided by MeteoSwiss, the Swiss Federal Office of Meteorology and Climatology. We are thankful to the Land-Climate Dynamics group of Sonia I. Seneviratne, Institute for Atmospheric and Climate Science (IAC), ETH Zurich for providing the data from the SwissSMEX network (http://www.iac. ethz.ch/group/land-climate-dynamics/research/swisssmex.html).

We also thank our colleagues from ARPA for supplying the data from the Cervinia field site and the PERMOS network for the weather and temperature data at Dreveneuse, Gemmi, Schilthorn and Stockhorn, as well as the resistivity data at Schilthorn. The IMIS data were kindly provided by the WSL Institute for Snow and Avalanche Research SLF. Special thanks to all the field helpers, who contributed to the network set-up. Moreover, we would like to thank Masaki Hayashi and Norbert Kalthoff as well as the editor and two anonymous referees for their detailed and helpful comments and suggestions.

Edited by: Roberto Greco

Reviewed by: two anonymous referees

\section{References}

Aragones, J. L., MacDowell, L. G., and Vega, C.: Dielectric Constant of Ices and Water: A Lesson about Water Interactions, J. Phys. Chem. A, 115, 5745-5758, https://doi.org/10.1021/jp105975c, 2011.

Barthlott, C., Hauck, C., Schaedler, G., Kalthoff, N., and Kottmeier, C.: Soil moisture impacts on convective indices and precipitation over complex terrain, Meteorol. Z., 20, 185-197, https://doi.org/10.1127/0941-2948/2011/0216, 2011.

Beltrami, H.: Active layer distortion of annual air soil thermal orbits, Permafrost Periglac., 7, 101-110, https://doi.org/10.1002/(SICI)10991530(199604)7:2<101::AID-PPP217>3.3.CO;2-3, 1996.

Beringer, J., Lynch, A. H., Chapin, F. S., Mack, M., and Bonan, G. B.: The Representation of Arctic Soils in the Land Surface Model: The Importance of Mosses, J. Climate, 14, 3324-3335, https://doi.org/10.1175/15200442(2001)014<3324:TROASI>2.0.CO;2, 2001.

Bircher, S., Skou, N., Jensen, K. H., Walker, J. P., and Rasmussen, L.: A soil moisture and temperature network for SMOS validation in Western Denmark, Hydrol. Earth Syst. Sci., 16, 14451463, https://doi.org/10.5194/hess-16-1445-2012, 2012. 
Bogena, H. R., Herbst, M., Huisman, J. A., Rosenbaum, U., Weuthen, A., and Vereecken, H.: Potential of Wireless Sensor Networks for Measuring Soil Water Content Variability, Vadose Zone J., 9, 1002-1013, https://doi.org/10.2136/vzj2009.0173, 2010.

Bogena, H. R., Huisman, J. A., Schilling, B., Weuthen, A., and Vereecken, H.: Effective Calibration of LowCost Soil Water Content Sensors, Sensors, 17, 208, https://doi.org/10.3390/s17010208, 2017.

Boike, J., Wille, C., and Abnizova, A.: Climatology and summer energy and water balance of polygonal tundra in the Lena River Delta, Siberia, J. Geophys. Res-Biogeo., 113, G03025, https://doi.org/10.1029/2007JG000540, 2008.

Borga, M., Boscolo, P., Zanon, F., and Sangati, M.: Hydrometeorological Analysis of the 29 August 2003 Flash Flood in the Eastern Italian Alps, J. Hydrometeorol., 8, 1049-1067, https://doi.org/10.1175/JHM593.1, 2007.

Brocca, L., Morbidelli, R., Melone, F., and Moramarco, T.: Soil moisture spatial variability in experimental areas of central Italy, J. Hydrol., 333, 356-373, https://doi.org/10.1016/j.jhydrol.2006.09.004, 2007.

Cosby, B. J., Hornberger, G. M., Clapp, R. B., and Ginn, T. R.: A Statistical Exploration of the Relationships of Soil Moisture Characteristics to the Physical Properties of Soils, Water Resour. Res., 20, 682-690, https://doi.org/10.1029/WR020i006p00682, 1984.

Delaloye, R.: Contribution à l'étude du pergélisol de montagne en zone marginale, $\mathrm{PhD}$ thesis, University of Fribourg, Switzerland, 240 pp., 2004.

Delaloye, R. and Lambiel, C.: Evidence of winter ascending air circulation throughout talus slopes and rock glaciers situated in the lower belt of alpine discontinuous permafrost (Swiss Alps), Norsk Geogr. Tidsskr., 59, 194-203, 2005.

Delta-T Devices.: User Manual for the Profile Probe type PR2, available at: http://www.delta-t.co.uk/product/pr2/\#support (last access: 19 June 2017), 2008.

Dorigo, W. A., Wagner, W., Hohensinn, R., Hahn, S., Paulik, C., Xaver, A., Gruber, A., Drusch, M., Mecklenburg, S., van Oevelen, P., Robock, A., and Jackson, T.: The International Soil Moisture Network: a data hosting facility for global in situ soil moisture measurements, Hydrol. Earth Syst. Sci., 15, 1675-1698, https://doi.org/10.5194/hess-15-1675-2011, 2011.

Dorigo, W. A., Xaver, A., Verugdenhil, M., Gruber, A., Hegyiová, A., Sanchis-Dufau, A. D., Zamojski, D., Cordes, C., Wagner, W., and Drusch, M.: Global Automated Quality Control of In Situ Soil Moisture Data from the International Soil Moisture Network, Vadose Zone J., 12, https://doi.org/10.2136/vzj2012.0097, 2013.

Gruber, S., King, L., Kohl, T., Herz, T., Haeberli, W., and Hoelzle, M.: Interpretation of geothermal profiles perturbed by topography: The Alpine Permafrost boreholes at Stockhorn Plateau, Switzerland, Permafrost Periglac., 15, 349-357, https://doi.org/10.1002/ppp.503, 2004.

Gude, M., Dietrich, S., Mäusbacher, R., Hauck, C., Molenda, R., Ruzicka, V., and Zacharda, M.: Probable occurence of sporadic permafrost in non-alpine scree slopes in central Europe, in: Proceedings of the 8th International Conference on Permafrost, Zurich, Switzerland, 20-25 July 2003, 331-336, 2003.
Harris, C., Haeberli, W., Vonder Muhll, D., and King, L.: Permafrost monitoring in the high mountains of Europe: the PACE project in its global context, Permafrost Periglac., 12, 3-11, https://doi.org/10.1002/ppp.377, 2001.

Hasler, A., Gruber, S., Font, M., and Dubois, A.: Advective heat transport in frozen rock clefts -conceptual model, laboratory experiments and numerical simulation, Permafrost Periglac., 22, 387-398, https://doi.org/10.1002/ppp.737, 2011.

Hauck, C.: Frozen ground monitoring using DC resistivity tomography, Geophys. Res. Lett., 29, 2016, https://doi.org/10.1029/2002GL014995, 2002.

Hauck, C., Barthlott, C., Krauss, L., and Kalthoff, N.: Soil moisture variability and its influence on convective precipitation over complex terrain, Q. J. Roy. Meteor. Soc., 137, 42-56, https://doi.org/10.1002/qj.766, 2011.

Hayashi, M.: The Cold Vadose Zone: Hydrological and Ecological Significance of Frozen-Soil Processes, Vadose Zone J., 12, https://doi.org/10.2136/vzj2013.03.0064, 2013.

Hilbich, C., Hauck, C., Hoelzle, M., Scherler, M., Schudel, L., Voelksch, I., Vonder Muehll, D., and Maeusbacher, R.: Monitoring mountain permafrost evolution using electrical resistivity tomography: A 7-year study of seasonal, annual, and long-term variations at Schilthorn, Swiss Alps, J. Geophys. Res.-Earth, 113, F01S90, https://doi.org/10.1029/2007JF000799, 2008.

Hilbich, C., Fuss, C., and Hauck, C.: Automated Timelapse ERT for Improved Process Analysis and Monitoring of Frozen Ground, Permafrost Periglac., 22, 306-319, https://doi.org/10.1002/ppp.732, 2011.

Hillel, D.: Introduction to environmental soil physics, Elsevier Academic Press, Amsterdam, 2004.

Hinkel, K. M., Paetzold, F., Nelson, F. E., and Bockheim, J. G.: Patterns of soil temperature and moisture in the active layer and upper permafrost at Barrow, Alaska: 1993-1999, Global Planet. Change, 29, 293-309, https://doi.org/10.1016/S09218181(01)00096-0, 2001.

Imhof, M., Pierrehumbert, G., Haeberli, W., and Kienholz, H.: Permafrost investigation in the Schilthorn massif, Bernese Alps, Switzerland, Permafrost Periglac., 11, 189-206, https://doi.org/10.1002/1099-1530(200007/09)11:3<189::AIDPPP348>3.0.CO;2-N, 2000.

IMKO: TRIME-PICO 64/32 Manual, available at: https: //imko.de/en/products/industrial-moisture/pico64 (last access: 19 June 2017), 2015.

King, L.: Soil and rock temperatures in discontinuous permafrost: Gornergrat and unterrothorn, wallis, Swiss alps, Permafrost Periglac., 1, 177-188, https://doi.org/10.1002/ppp.3430010208, 1990.

Kneisel, C., Hauck, C., and Vonder Muhll, D.: Permafrost below the timberline confirmed and characterized by geoelectrical resistivity measurements, Bever Valley, eastern Swiss Alps, Permafrost Periglac., 11, 295-304, https://doi.org/10.1002/10991530(200012)11:4<295::AID-PPP353>3.0.CO;2-L, 2000.

Krauss, L., Hauck, C., and Kottmeier, C.: Spatio-temporal soil moisture variability in Southwest Germany observed with a new monitoring network within the COPS domain, Meteorol. Z., 19, 523-537, https://doi.org/10.1127/0941-2948/2010/0486, 2010.

Krautblatter, M., Huggel, C., Deline, P., and Hasler, A.: Research Perspectives on Unstable High-alpine Bedrock Permafrost: Mea- 
surement, Modelling and Process Understanding, Permafrost Periglac., 23, 80-88, https://doi.org/10.1002/ppp.740, 2012.

Krummenacher, B. and Budmiger, K.: Monitoring of Periglacial Phenomena in the Furggentalti Swiss Alps, Permafrost Periglac., 3, 149-155, https://doi.org/10.1002/ppp.3430030213, 1992.

Krummenacher, B., Mihajlovic, D., Nussbaum, A., and Staub, B. (Eds.): 20 Jahre Furggentälti - Permafrostuntersuchungen auf der Gemmi, Geographica Bernensia, Bern, Switzerland, 113 pp., 2008.

Martini, E., Wollschläger, U., Kögler, S., Behrens, T., Dietrich, P., Reinstorf, F., Schmidt, K., Weiler, M., Werban, U., and Zacharias, S.: Spatial and Temporal Dynamics of Hillslope-Scale Soil Moisture Patterns: Characteristic States and Transition Mechanisms, Vadose Zone J., 14, https://doi.org/10.2136/vzj2014.10.0150, 2015.

MeteoSwiss: Daily Precipitation (final analysis): RhiresD, Documentation of MeteoSwiss Grid-Data Products, available at: http: //www.meteosuisse.admin.ch/home/recherche.subpage.html/fr/ data/products/2014/donnees-spatiales-de-precipitations.html (last access: 19 June 2017), 2014.

MeteoSwiss: Bulletin climatologique année 2015, Geneva, available at: http://www.meteosuisse.admin.ch/home/climat/actuel/ rapports-climatiques.html (last access: 19 June 2017), 2016.

Mittelbach, H. and Seneviratne, S. I.: A new perspective on the spatio-temporal variability of soil moisture: temporal dynamics versus time-invariant contributions, Hydrol. Earth Syst. Sci., 16, 2169-2179, https://doi.org/10.5194/hess-16-2169-2012, 2012.

Mittelbach, H., Casini, F., Lehner, I., Teuling, A. J., and Seneviratne, S. I.: Soil moisture monitoring for climate research: Evaluation of a low-cost sensor in the framework of the Swiss Soil Moisture Experiment (SwissSMEX) campaign, J. Geophys. Res.-Atmos., 116, D05111, https://doi.org/10.1029/2010JD014907, 2011.

Mittelbach, H., Lehner, I., and Seneviratne, S. I.: Comparison of four soil moisture sensor types under field conditions in Switzerland, J. Hydrol., 430, 39-49, https://doi.org/10.1016/j.jhydrol.2012.01.041, 2012.

Morard, S.: Effets de la circulation d'air par effet de cheminée dans l'évolution du régime thermique des éboulis froids de basse et moyenne altitude, PhD thesis, University of Fribourg, Switzerland, 220 pp., 2011.

Morbidelli, R., Saltalippi, C., Flammini, A., Corradini, C., Brocca, L., and Govindaraju, R. S.: An investigation of the effects of spatial heterogeneity of initial soil moisture content on surface runoff simulation at a small watershed scale, J. Hydrol., 539, 589-598, https://doi.org/10.1016/j.jhydrol.2016.05.067, 2016.

Outcalt, S. I., Nelson, F. E., and Hinkel, K. M.: The zerocurtain effect: Heat and mass transfer across an isothermal region in freezing soil, Water Resour. Res., 26, 1509-1516, https://doi.org/10.1029/WR026i007p01509, 1990.

Paschalis, A., Fatichi, S., Katul, G. G., and Ivanov, V. Y.: Cross-scale impact of climate temporal variability on ecosystem water and carbon fluxes, J. Geophys. Res.-Biogeo., 120, 2015JG003002, https://doi.org/10.1002/2015JG003002, 2015.

Pellet, C., Hilbich, C., Marmy, A., and Hauck, C.: Soil Moisture Data for the Validation of Permafrost Models Using Direct and Indirect Measurement Approaches at Three Alpine Sites, Front. Earth Sci., 3, 91, https://doi.org/10.3389/feart.2015.00091, 2016.
PERMOS: Permafrost in Switzerland 2010/2011 to 2013/2014, Glaciological Report (Permafrost) of the Cryospheric Commission of the Swiss Academy of Sciences No. 12-15, Fribourg, Switzerland, 85 pp., 2016.

Pogliotti, P., Guglielmin, M., Cremonese, E., Morra di Cella, U., Filippa, G., Pellet, C., and Hauck, C.: Warming permafrost and active layer variability at Cime Bianche, Western European Alps, The Cryosphere, 9, 647-661, https://doi.org/10.5194/tc-9-6472015, 2015.

Porporato, A., Daly, E., Rodriguez-Iturbe, I., and Fagan, A. E. W. F.: Soil Water Balance and Ecosystem Response to Climate Change, The American Naturalist, 164, 625-632, https://doi.org/10.1086/424970, 2004.

Python, S.: Technical improvement of the 4-phase model to better assess the ice, water and air content estimation in permafrost substrate. Case Study: Stockhorn, Valais, Switzerland, MSc thesis, University of Fribourg, Switzerland, 135 pp., 2015.

Qu, W., Bogena, H. R., Huisman, J. A., and Vereecken, H.: Calibration of a Novel Low-Cost Soil Water Content Sensor Based on a Ring Oscillator, Vadose Zone J., 12, https://doi.org/10.2136/vzj2012.0139, 2013.

Rajczak, J., Kotlarski, S., Salzmann, N., and Schär, C.: Robust climate scenarios for sites with sparse observations: a twostep bias correction approach, Int. J. Climatol., 36, 1226-1243, https://doi.org/10.1002/joc.4417, 2016.

Rautiainen, K., Lemmetyinen, J., Pulliainen, J., Vehvilainen, J., Drusch, M., Kontu, A., Kainulainen, J., and Seppanen, J.: L-Band Radiometer Observations of Soil Processes in Boreal and Subarctic Environments, Ieee T. Geosci. Remote, 50, 1483-1497, https://doi.org/10.1109/TGRS.2011.2167755, 2012.

Rist, A. and Phillips, M.: First results of investigations on hydrothermal processes within the active layer above alpine permafrost in steep terrain, Norsk Geogr. Tidsskr., 59, 177-183, https://doi.org/10.1080/00291950510020574, 2005.

Robinson, D. A.: Measurement of the solid dielectric permittivity of clay minerals and granular samples using a time domain reflectometry immersion method, Vadose Zone J., 3, 705-713, 2004.

Robinson, D. A., Campbell, C. S., Hopmans, J. W., Hornbuckle, B. K., Jones, S. B., Knight, R., Ogden, F., Selker, J., and Wendroth, O.: Soil Moisture Measurement for Ecological and Hydrological Watershed-Scale Observatories: A Review, Vadose Zone J., 7, 358-389, https://doi.org/10.2136/vzj2007.0143, 2008.

Sawada, Y., Ishikawa, M., and Ono, Y.: Thermal regime of sporadic permafrost in a block slope on Mt. Nishi-Nupukaushinupuri, Hokkaido Island, Northern Japan, Geomorphology, 52, 121-130, https://doi.org/10.1016/S0169-555X(02)00252-0, 2003.

Scherler, M., Hauck, C., Hoelzle, M., Staehli, M., and Voelksch, I.: Meltwater Infiltration into the Frozen Active Layer at an Alpine Permafrost Site, Permafrost Periglac., 21, 325-334, https://doi.org/10.1002/ppp.694, 2010.

Scherrer, S. C., Fischer, E. M., Posselt, R., Liniger, M. A., Croci-Maspoli, M., and Knutti, R.: Emerging trends in heavy precipitation and hot temperature extremes in Switzerland, J. Geophys. Res.-Atmos., 121, 2626-2637, https://doi.org/10.1002/2015JD024634, 2016.

Seneviratne, S. I., Corti, T., Davin, E. L., Hirschi, M., Jaeger, E. B., Lehner, I., Orlowsky, B., and Teuling, A. J.: Investigating soil moisture-climate interactions in a 
changing climate: A review, Earth-Sci. Rev., 99, 125-161, https://doi.org/10.1016/j.earscirev.2010.02.004, 2010.

Smith, R. B.: The influence of mountains on the atmosphere, Adv. Geophys., 21, 87-220, 1979.

Spaans, E. J. A. and Baker, J. M.: Examining the use of time domain reflectometry for measuring liquid water content in frozen soil, Water Resour. Res., 31, 2917-2925, https://doi.org/10.1029/95WR02769, 1995.

Starr, J. L. and Paltineanu, I. C.: Methods for measurement of soil water content: Capacitance devices, in: Methods of Soil Analysis: Part 4 Physical Methods, edited by: Dane, J. H. and Topp, G. C., Soil Science Society of America, Inc., Madison, USA, 463474, 2002.

Staub, B. and Delaloye, R.: Using Near-Surface Ground Temperature Data to Derive Snow Insulation and Melt Indices for Mountain Permafrost Applications, Permafrost Periglac., 28, 237-248, https://doi.org/10.1002/ppp.1890, 2017.

Streletskiy, D., Anisimov, O., and Vasiliev, A.: Permafrost degradation, in: Snow and Ice-related Hazards, Risks and Disasters, edited by: Haeberli, W., Whiteman, C., and Shroder, J. F., Elsevier, Boston, 303-344, 2014.

Topp, G., Davis, J., and Annan, A.: Electromagnetic Determination of Soil-Water Content - Measurements in Coaxial Transmission-Lines, Water Resour. Res., 16, 574-582, https://doi.org/10.1029/WR016i003p00574, 1980.

Truebner:: SMT100 soil moisture sensor, available at: http://www. truebner.de/en/smt100 (last access: 19 June 2017), 2016.

Vereecken, H., Huisman, J. A., Pachepsky, Y., Montzka, C., van der Kruk, J., Bogena, H., Weihermueller, L., Herbst, M., Martinez, G., and Vanderborght, J.: On the spatio-temporal dynamics of soil moisture at the field scale, J. Hydrol., 516, 76-96, https://doi.org/10.1016/j.jhydrol.2013.11.061, 2014.

Verhoef, A., Fernandez-Galvez, J., Diaz-Espejo, A., Main, B. E., and El-Bishti, M.: The diurnal course of soil moisture as measured by various dielectric sensors: Effects of soil temperature and the implications for evaporation estimates, J. Hydrol., 321, 147-162, https://doi.org/10.1016/j.jhydrol.2005.07.039, 2006.

Wakonigg, H.: Unterkühlte Schutthalden. Beiträge zur Permafrostforschung in Österreich, Arbeiten Aus Dem Inst. F. Geogr. KarlFranzens-Universität Graz, 33, 209-223, 1996.

Westermann, S., Lüers, J., Langer, M., Piel, K., and Boike, J.: The annual surface energy budget of a high-arctic permafrost site on Svalbard, Norway, The Cryosphere, 3, 245-263, https://doi.org/10.5194/tc-3-245-2009, 2009.
Watanabe, K. and Wake, T.: Measurement of unfrozen water content and relative permittivity of frozen unsaturated soil using NMR and TDR, Cold Reg. Sci. Technol., 59, 34-41, https://doi.org/10.1016/j.coldregions.2009.05.011, 2009.

Wicki, A.: Spatial and temporal variability of soil moisture and the influence on the thermal regime of permafrost at the Schilthorn (Bernese Alps), MSc thesis, University of Fribourg, Fribourg, Switzerland, 107 pp., 2015.

Wicky, J. and Hauck, C.: Numerical modelling of convective heat transport by air flow in permafrost talus slopes, The Cryosphere, 11, 1311-1325, https://doi.org/10.5194/tc-11-1311-2017, 2017.

Wiekenkamp, I., Huisman, J. A., Bogena, H. R., Lin, H. S., and Vereecken, H.: Spatial and temporal occurrence of preferential flow in a forested headwater catchment, J. Hydrol., 534, 139149, https://doi.org/10.1016/j.jhydrol.2015.12.050, 2016.

Wraith, J. M. and Or, D.: Temperature effects on soil bulk dielectric permittivity measured by time domain reflectometry: Experimental evidence and hypothesis development, Water Resour. Res., 35, 361-369, https://doi.org/10.1029/1998WR900006, 1999.

Yoshikawa, K. and Overduin, P. P.: Comparing unfrozen water content measurements of frozen soil using recently developed commercial sensors, Cold Reg. Sci. Technol., 42, 250-256, https://doi.org/10.1016/j.coldregions.2005.03.001, 2005.

Zehe, E., Graeff, T., Morgner, M., Bauer, A., and Bronstert, A.: Plot and field scale soil moisture dynamics and subsurface wetness control on runoff generation in a headwater in the Ore Mountains, Hydrol. Earth Syst. Sci., 14, 873-889, https://doi.org/10.5194/hess-14-873-2010, 2010.

Zenklusen Mutter, E. and Phillips, M.: Active Layer Characteristics At Ten Borehole Sites In Alpine Permafrost Terrain, Switzerland, Permafrost Periglac., 23, 138-151, https://doi.org/10.1002/ppp.1738, 2012.

Zhou, X., Buchli, T., Kinzelbach, W., Stauffer, F., and Springman, S. M.: Analysis of Thermal Behaviour in the Active Layer of Degrading Mountain Permafrost, Permafrost Periglac., 26, 3956, https://doi.org/10.1002/ppp.1827, 2015. 